\title{
Macroeconomic Effects of Federal Reserve Forward Guidance
}

\begin{abstract}
A large output gap accompanied by stable inflation close to its target calls for further monetary accommodation, but the zero lower bound on interest rates has robbed the Federal Open Market Committee (FOMC) of the usual tool for its provision. We examine how public statements of FOMC intentions - forward guidance — can substitute for lower rates at the zero bound. We distinguish between Odyssean forward guidance, which publicly commits the FOMC to a future action, and Delphic forward guidance, which merely forecasts macroeconomic performance and likely monetary policy actions. Others have shown how forward guidance that commits the central bank to keeping rates at zero for longer than conditions would otherwise warrant can provide monetary easing, if the public trusts it. We empirically characterize the responses of asset prices and private macroeconomic forecasts to FOMC forward guidance, both before and since the recent financial crisis. Our results show that the FOMC has extensive experience successfully telegraphing its intended adjustments to evolving conditions, so communication difficulties do not present an insurmountable barrier to Odyssean forward guidance. Using an estimated dynamic stochastic general equilibrium model, we investigate how pairing such guidance with bright-line rules for launching rate increases can mitigate risks to the Federal Reserve's price stability mandate.
\end{abstract}

\footnotetext{
F
} rom the onset of the financial crisis and through the Great Recession and ensuing modest recovery, the Federal Open Market Committee (FOMC) of the Federal Reserve has commented upon the likely duration of monetary policy accommodation in the formal statement that follows each of its meetings. In December 2008 it said, "The Committee anticipates that weak economic conditions are likely to warrant exceptionally low 
levels of the federal funds rate for some time." In March 2009, when the first round of large-scale purchases of Treasury securities was announced, "an extended period" replaced "some time" in the formal statement. The August 2011 FOMC statement gave specificity to "an extended period" by announcing that the committee expected the funds rate to remain exceptionally low until "at least . . mid-2013." The January 2012 statement lengthened the anticipated period of exceptionally low rates even further, to "late 2014," language that remained in the March 2012 statement. Such communications of monetary authorities' intentions are referred to as forward guidance.

The nature of this most recent forward guidance by the FOMC is the subject of substantial debate. Studies by Paul Krugman (1999) and by Gauti Eggertsson and Michael Woodford (2003) before the recent episode and by Iván Werning (2012) more recently suggest that a monetary policymaker encountering the zero lower bound (ZLB) on the policy interest rate can stimulate current aggregate demand by credibly promising to keep the rate at zero longer than required by economic conditions and thereby creating an economic boom in the future. One might interpret "late 2014" as such a credible promise, but one also might interpret it as merely describing what the FOMC's policy reaction function would prescribe if current forecasts of sluggish economic activity and low inflation through that date come to pass. "Late 2014" predicts unusually accommodative policy whenever the underlying policy reaction function would dictate an earlier "liftoff" of the funds rate from zero given the identical conditioning data.

Motivated by these competing interpretations of "late 2014," we distinguish between two kinds of forward guidance. Delphic forward guidance publicly states a forecast of macroeconomic performance and likely or intended monetary policy actions based on the policymaker's potentially superior information about future macroeconomic fundamentals and its own policy goals. ${ }^{2}$ Such forward guidance presumably improves macroeconomic outcomes by reducing private decisionmakers' uncertainty.

1. Since one of the authors regularly attends meetings of the FOMC, it may be tempting just to ask him this question directly. The vantage point of this paper is a research inquiry: how can these questions be answered from the standpoint of economic researchers with only publicly available information?

2. The classical Delphic oracle famously made ambiguous utterances. We do not mean "Delphic" in this sense. We use the term simply to describe FOMC statements about the future. 
Importantly, however, it does not publicly commit the policymaker to a particular course of action. Odyssean forward guidance, in contrast, does publicly commit the policymaker, just as Odysseus committed himself to staying on his ship by having himself bound to the mast. Tying one's hands in the face of an uncertain future might seem like a foolish sacrifice for no apparent gain, but economic fluctuations routinely present opportunities for monetary policy to benefit from issuing Odyssean forward guidance. The reason is that by so doing, policymakers can change public expectations of their actions tomorrow in a way that improves macroeconomic performance today. ${ }^{3}$

Nevertheless, the implementation of Odyssean policy faces a fundamental challenge. When the appointed time for action arrives, any beneficial effects of the policy's anticipation will be bygones that nothing can change. Therefore, both the monetary policymaker and the public will at that later time prefer a policy that addresses only the present circumstances and ignores the beneficial effects of its anticipation on past macroeconomic performance. For example, when it comes time to keep an earlier promise to raise aggregate demand, the FOMC will be concerned about its price stability mandate and, acting as it has always done in normal times, will not want to follow through. ${ }^{4}$ Just as Odysseus anticipated that on hearing the Sirens' song he would regret his commitment to stay aboard his ship, so might monetary policymakers anticipate regretting their commitment to ease policy. If the public understands this and therefore believes that such promises will not be kept, they will not have the intended effect. Odysseus could use the rope that bound him to the mast to enforce his commitment. Lacking such an enforcement mechanism, monetary policymakers must rely on their reputations for accuracy and honesty to make their commitments credible.

The Odyssean monetary policies elucidated by Krugman, Eggertsson and Woodford, and Werning have inspired several recent proposals to provide more accommodation at the ZLB. The more aggressive policy alternatives that have been proposed include Evans's (2012) state-contingent price-level targeting, nominal income targeting as advocated by Christina Romer, ${ }^{5}$ and

3. Romer and Romer (2000) and Ellingsen and Söderström (2001) characterize forward guidance similarly.

4. This is an example of a time-inconsistent policy, first considered by Kydland and Prescott (1977).

5. Christina D. Romer, "Dear Ben: It's Time for Your Volcker Moment," The New York Times, October 29, 2011. 
conditional economic thresholds for exiting the ZLB as proposed by Evans (2011). The main challenge facing the FOMC in implementing any of these policies is convincing the public that it will follow through on the promised future course of action. This paper sheds light on the FOMC's ability to meet this challenge and on the possible benefits of doing so.

The FOMC has used forward guidance implicitly, through speeches and testimony by its members, and explicitly, through formal committee statements, since long before the financial crisis, so the question of whether the FOMC can clearly communicate its future policy intentions can be addressed empirically. Accordingly, the first part of this paper examines data from before and after the crisis, to measure the impact that FOMC communications have had on private expectations. We begin by studying market responses to FOMC statements, building on prior work by Refet Gürkaynak, Brian Sack, and Eric Swanson (2005). Those authors follow Kenneth Kuttner (2001) by analyzing changes in prices on federal funds rate futures in short windows of time surrounding the release of FOMC statements. Using a sample from June 1991 through December 2004, Gürkaynak and his coauthors find that FOMC statements are associated with significant effects, both on federal funds futures prices and on Treasury yields, that are not due to surprise changes in the federal funds target itself. That is, their results show that market participants believe that FOMC statements contain reliable information about future monetary policy actions. We verify that these findings continue to hold when the sample is extended to July 2007, just before the crisis.

One might doubt the relevance of these findings for the present situation, because the attainment of the ZLB has robbed the FOMC of its principal policy lever. But evidence exists that the FOMC can still exert influence in the presence of a binding ZLB. Focusing on FOMC communications about its recent large-scale asset purchases, known as QE1 and QE2, Joseph Gagnon and coauthors (2010) and Arvind Krishnamurthy and Annette Vissing-Jorgensen (2011) provide evidence of significant asset price effects since the crisis. To complement these studies and provide more assurance that forward guidance unaccompanied by material policy action can move asset prices, we apply Gürkaynak and his coauthors' methodology to FOMC statements since the crisis and find results similar to theirs.

FOMC actions that influence asset prices are merely means toward the end of fulfilling the Federal Reserve's dual mandate of maximum sustainable employment and price stability. To evaluate the contributions of 
FOMC statements toward this ultimate goal, we examine how revisions to the Blue Chip consensus forecasts of the unemployment rate and consumer price index (CPI) inflation respond to the policy innovations identified by Gürkaynak and others (2005). For the sample period February 1994 to June 2007, a positive innovation to future federal funds rates is associated with decreases in unemployment forecasts for the subsequent 3 quarters and with higher forecasts of CPI inflation in the current and subsequent quarters. We never find a statistically significant reaction of either forecast that is of the "correct" sign, that is, one that indicates a New Keynesian response to an exogenous policy shock. From this we conclude that the monetary policy surprises identified with high-frequency data have a substantial Delphic component, despite the fact that the methodology of Gürkaynak and others inherently controls for publicly known macroeconomic fundamentals. That is, professional forecasters infer that the FOMC's unexpected policy adjustments are responses to nonpublic information that the FOMC possesses regarding the future strength of the economy. ${ }^{6}$ We find qualitatively similar results for the crisis period, but the estimates are too imprecise to allow firm quantitative conclusions.

The FOMC does not rely solely on postmeeting public statements to communicate its policies. To get a broader perspective on the influence of FOMC communications on private expectations, we proceed to examine monetary policy surprises identified from a simple interest rate rule like those of John Taylor $(1993,1999)$ and David Reifschneider and John Williams (2000). Using the Blue Chip forecasts and interest rate futures prices aggregated to the quarterly level, we estimate such a rule and decompose its residual into the part revealed when the spot policy rate is set and the parts revealed to the public in the prior 4 quarters.

We highlight here four results based on data from 1996 through 2007. First, the standard deviation of the expected interest rate 4 quarters out minus its value from the rule is only 9 basis points (bp). Thus, the rule describes medium-run forecasts of FOMC behavior extremely well. Apparently, the FOMC has been successful in communicating its typical behavior to the public. Although this need not reflect an Odyssean commitment, it is observationally equivalent to one. Second, the FOMC telegraphs

6. Such information might reflect the Federal Reserve staff's possibly superior ability to process incoming data. It does not have to involve proprietary access to data or information held only by the FOMC about its future policy intentions. 
40 percent of its deviations from the interest rate rule exactly 1 quarter in advance and another 40 percent 2 or more quarters in advance. Third, the identified forward guidance residuals have much stronger effects on asset prices than do surprises of the type described by Gürkaynak and others (2005). For example, a 1-bp innovation to next quarter's expected federal funds rate moves both the 2-year and the 5-year Treasury rate by about $2 \mathrm{bp}$. The corresponding effects estimated with the methodology of Gürkaynak and others are under $1 \mathrm{bp}$. Fourth, the identified forward guidance residuals are negatively correlated with unemployment forecast revisions and positively correlated with inflation forecast revisions, just like the statement date-based shocks in Gürkaynak and others (2005). Apparently, the residuals reflect, at least in part, anticipated deviations from the policy rule that nevertheless are motivated by recent news of economic fundamentals. Phrased differently, the FOMC's behavior has been history dependent: the committee reacts more aggressively to economic weakness revealed only shortly before its onset than to weakness foreseen 4 quarters in advance.

The estimated effects of FOMC forward guidance on asset prices and private forecasts suggest that the FOMC has had some success in communicating its future intentions to the public. ${ }^{7}$ This suggests that communication difficulties do not present an insurmountable barrier to monetary policy based on Odyssean forward guidance. The second part of our paper investigates the consequences of interpreting the "late 2014" statement language as Odyssean forward guidance that implements the policy recommendations of Eggertsson and Woodford (2003) and others. There are legitimate concerns that forward guidance of this kind places the FOMC's mandated price stability goal at risk. We consider these concerns by forecasting the path of the economy with the present forward guidance and subjecting that forecast to two upside risks: higher inflation expectations and faster deleveraging by households and firms.

This policy analysis uses a medium-scale dynamic stochastic general equilibrium (DSGE) model adapted from Justiniano, Giorgio Primiceri, and Andrea Tambalotti (2011) at the Federal Reserve Bank of Chicago. The model strongly resembles other medium-scale DSGE models in the

7. Both our inferences of forward guidance and those from the more familiar event-study approach use market prices to measure the quantitative content of FOMC communication. In standard models the process of communication is transparent and frictionless, so it is tempting to suppose that the FOMC can fine-tune its statements to achieve any desired market impact. However, one must acknowledge frictions in the communication process that make market responses to FOMC statements unpredictable to the FOMC itself. 
literature and is very similar to models used at central banks around the world. ${ }^{8}$ Importantly for our purposes, it embodies the basic mechanisms that make forward guidance attractive at the ZLB.

Evans (2011) has proposed that the FOMC pledge to begin lifting its policy rate from zero if either the unemployment rate falls below 7 percent or expected inflation over the medium term rises above 3 percent. This " $7 / 3$ " threshold rule is designed to maintain low interest rates even as the economy begins expanding on its own (as prescribed by Eggertsson and Woodford 2003), while providing safeguards against unexpected developments that may put the FOMC's price stability mandate in jeopardy. Our policy analysis suggests that such conditioning, if credible, could be helpful in limiting the inflationary consequences of a surge in aggregate demand arising from an early end to the deleveraging observed since the financial crisis.

\section{FOMC Statements and Private Expectations}

The FOMC's use of forward guidance since long before the financial crisis makes it possible to assess empirically its ability to communicate its future policy intentions. In this section we do so by applying the methodology of Gürkaynak, Sack, and Swanson (2005; GSS henceforth). They use high-frequency data on prices of federal funds futures and Eurodollar futures contracts to measure unanticipated changes in expected future spot interest rates associated with FOMC statements. Two estimated factors, a target factor that moves the current policy rate and a path factor that moves only expected future rates, account for most of these changes. GSS show that yields on longer-duration Treasury notes respond substantially to the path factor.

We extend the GSS analysis in three ways. First, we examine the responses of yields on corporate bonds to the factors and confirm that a positive realization of the path factor raises not only expected future policy rates but corporate borrowing rates as well. That is, forward guidance influences interest rates that are directly relevant for private investment decisions. Second, we examine how revisions to professional forecasts of unemployment and CPI inflation respond to the factors. If the public and the FOMC were equally well informed about macroeconomic fundamentals, then the factors must reflect the revelation of FOMC policy preferences. In that case one would expect forecast revisions to match the equilibrium response to an

8. The FOMC's minutes for the June 2011 meeting describe a discussion of DSGE models within the Federal Reserve System at that meeting. 
unanticipated monetary policy shock. Instead, however, we find that the statistically significant responses all have the sign opposite to that predicted by the standard New Keynesian model: unanticipated increases in the path factor lead to decreases in expected unemployment and increases in expected inflation. From this we conclude that professional forecasters believe that FOMC policy surprises contain useful and otherwise unavailable macroeconomic information - that is, they have a Delphic component. Third, we extend the sample period so as to examine FOMC announcements since the onset of the financial crisis in August 2007. Here the relatively small sample makes our estimates of professional forecasters' responses to surprise monetary policy moves too imprecise to allow firm conclusions, but the estimates of asset price responses remain accurate enough to show that they differ little from their precrisis values.

\section{I.A. Forward Guidance before the Financial Crisis}

Glenn Rudebusch and Williams (2008) describe the modern history of explicit forward guidance before the financial crisis. From 1983 to 1999 the FOMC's views about the future policy path were put to a vote at each meeting. The vote was on the expected direction of future changes in the stance of policy between meetings. However, this information was made public only after the following meeting, when it was outdated and presumably of limited use to the public. In February 1994 the FOMC began issuing immediately after each meeting a statement describing the current policy stance, and in May 1999 it began including explicit language about the future stance of policy in these statements. The first of these forward-looking statements read in part as follows: "The Committee ... adopted a directive that is tilted toward the possibility of a firming in the stance of monetary policy." The language intended to guide expectations has changed over time as the FOMC has sought ways of maintaining transparency without confusing markets, and as it has adjusted to the evolving policy environment. But language of one form or another describing the expected future stance of policy has come to be a fixture of these statements. ${ }^{9}$

9. Here are some examples. At the start of 2000 , the direct signals of policy inclinations were replaced with language describing the "balance of risks" regarding the FOMC's mandated goals of maximum employment and price stability. The August 2003 FOMC statement said, "The Committee believes that policy accommodation can be maintained for a considerable period." In January 2004 the forward-looking language was "the Committee believes that it can be patient in removing its policy accommodation," and that of May 2004 was "policy accommodation can be removed at a pace that is likely to be measured." As inflation fears rose thereafter, the December 2005 statement included the words "further policy firming may be needed." 
When measuring the market impact of FOMC statements, one must confront the possibility that their content is more confirming of macroeconomic conditions already known by market participants than revealing of adjustments to policy. Failure to control for statements' confirming content could lead to incorrectly attributing to them outcomes that are in fact due to other factors driving revisions to expectations of growth and inflation. GSS overcome this difficulty by studying the behavior of expected federal funds rates in symmetric 30- and 60-minute windows surrounding the release of FOMC statements. Focusing on these narrow windows keeps the economic information available to market participants essentially fixed.

The within-day data on which GSS rely are unavailable to us after 2004, so we extend their work using daily observations of implied future interest rates at the market's close from five futures contracts: the current-month and 3-month-ahead federal funds futures contracts (with a scale factor to account for the timing of FOMC meetings within the month) and the 2-, 3-, and 4-quarter-ahead Eurodollar futures contracts (adjusted by the difference between the spot Eurodollar and federal funds rates); to each of these we add a risk premium of $1 \mathrm{bp}$ per month. ${ }^{10}$ Using data from the same contracts spanning February 1990 through February 2004, GSS find that just two factors explain more than 90 percent of the variation in these contracts' prices. Despite the potentially unlimited complexity of monetary policy statements, financial markets nonetheless have reacted as if there is essentially only one additional degree of information beyond surprise changes in the federal funds rate target. By performing a suitable rotation of the two factors, GSS show that they can be given "target" and "path" interpretations. The target factor accounts for most of the surprise change in the current federal funds rate. By construction, the path factor influences only expected future rates. ${ }^{11}$

We begin our analysis by replicating theirs over a slightly longer time sample, February 1990 through June 2007. We have found that many of

10. Our use of the daily window should not be too problematic, since GSS's results are similar when they use the daily window (see their table 1). The short windows studied by GSS are mostly relevant for the period before February 1994, when open-market operations were sometimes conducted following the release of labor market data on the same day.

11. GSS show that the path factor is associated with well-known significant changes in FOMC statement language. For example, its largest realization in absolute value occurs on January 28, 2004, when the federal funds target was not changed but the phrase "policy accommodation can be maintained for a considerable period" was replaced with "the Committee believes it can be patient in removing its policy accommodation." This change in language was interpreted by markets as indicating that the FOMC would begin tightening policy sooner than previously expected. 
Table 1. Decomposing the Variance in Changes in Expected Federal Funds Rates, 1990-2007 and 1994-2007

Percent

\begin{tabular}{lccccc}
\hline & \multicolumn{3}{c}{ Share of variance due to indicated factor } \\
\cline { 2 - 3 } $\begin{array}{l}\text { Federal funds rate } \\
\text { futures contract }\end{array}$ & \multicolumn{2}{c}{$\begin{array}{c}\text { February 1990-June 2007 } \\
\text { sample }\end{array}$} & & \multicolumn{2}{c}{$\begin{array}{c}\text { February 1994-June 2007 } \\
\text { sample }\end{array}$} \\
\cline { 2 - 3 } \cline { 5 - 6 } & Target factor & Path factor & & Target factor & Path factor \\
\hline Current quarter & 98 & 0 & & 97 & 0 \\
Next quarter & 82 & 14 & & 74 & 22 \\
Two quarters hence & 51 & 47 & & 31 & 67 \\
Three quarters hence & 36 & 63 & & 18 & 81 \\
Four quarters hence & 21 & 77 & & 7 & 90 \\
\hline
\end{tabular}

Source: Authors' calculations.

a. Expected interest rates are measured using daily federal funds futures prices and Eurodollar futures prices as described in the text. Numbers do not sum to 100 because the two factors do not explain all the variation in the expected rate changes.

our results are sensitive to including the observation for September 2001, so we omit it from this and all subsequent analysis in this section (as do GSS in their online appendix). The first two columns of table 1 report the fractions of innovation variance for each interest rate futures contract rate that are due to the identified target factor and to the identified path factor over this sample period. The path factor accounts for no changes to the current quarter's interest rate by construction, and it accounts for only 14 percent of the variance in the interest rates expected for the next quarter. The target factor accounts for nearly all of the remaining variance from these two contracts. The path and target factors each explain about 50 percent of the variance in interest rates expected 2 quarters hence, and the path factor accounts for the clear majority of the variance in the two longest contracts.

Before February 1994 the FOMC did not explicitly announce changes in its target for the federal funds rate. Although GSS show that even before that date, market participants were able to discern within minutes of an open-market operation whether the FOMC had changed its target, one might reasonably suspect that little forward guidance came out of these earlier FOMC meetings. The second two columns of table 1 report the results when we discard these first 4 years. As expected, this change in the sample period increases the path factor's importance.

GSS document substantial positive statistical relationships between their identified factors and yields on financial assets. In particular, a positive 100-bp realization of their target factor raises 2-, 5-, and 10-year Treasury yields by 41,37 , and 28 bp, respectively (penultimate column 
of their table 5). Table 2 reports analogous regressions for the path and target factors as we identify them for the two samples. (We normalize the target factor loading on the current funds rate and the path factor loading on the 4-quarters-ahead futures rate to be unity. GSS use a slightly different normalization. The normalization has no impact on statistical significance or decomposition of variance.) The table's top panel reports the regressions using the 2-, 5-, and 10-year Treasury yields. GSS find that the two factors explain 94 percent, 80 percent, and 74 percent of the variance in these rate changes, respectively. The two factors we identify have similarly strong explanatory power for both samples we consider. For the longer sample (first two columns), all of the slopes multiplying the factors are positive and statistically significant at the 1 percent level. Their magnitudes are comparable to those reported by GSS, but our path factor slopes are somewhat larger and our target factor slopes a bit smaller than theirs. For the sample excluding the period without regular post-FOMC meeting statements (last two columns), the target factor's slopes are smaller and those of the path factor larger than for the longer sample. The table's bottom panel reports the results using yields on Aaa/AAA- and Baa/BBB-rated corporate bonds with at least 20 years remaining before maturity. We find these to be of particular interest because they correspond to interest rates that are directly relevant for firms' investment decisions. Surprisingly to us, the target factor has no detectable influence on these yields, regardless of which sample we use. In contrast, a 100-bp positive path factor realization raises both yields by about 30 to $35 \mathrm{bp}$, depending on the sample used for estimation.

Our first substantial extension of GSS uses the identified factors and observations of private inflation and unemployment expectations to measure the macroeconomic effects of forward guidance. For this analysis we rely on the Blue Chip Economic Indicators forecast survey. At the beginning of each month, Blue Chip solicits projections for key economic variables, including quarterly changes in the CPI and the civilian unemployment rate, from about 50 private forecasters. From these it compiles a "consensus" forecast for each variable, which is then published on the 10th of the month. The forecasts cover the previous quarter's data (which might not yet be published at the time of the survey) and each quarter in the current and next calendar years. Therefore, the data always report a 1-quarter backcast, a current-quarter nowcast, and forecasts for at least the next 4 quarters. ${ }^{12}$

12. The quarterly unemployment rate is expressed as the average monthly value across the quarter's constituent months. 


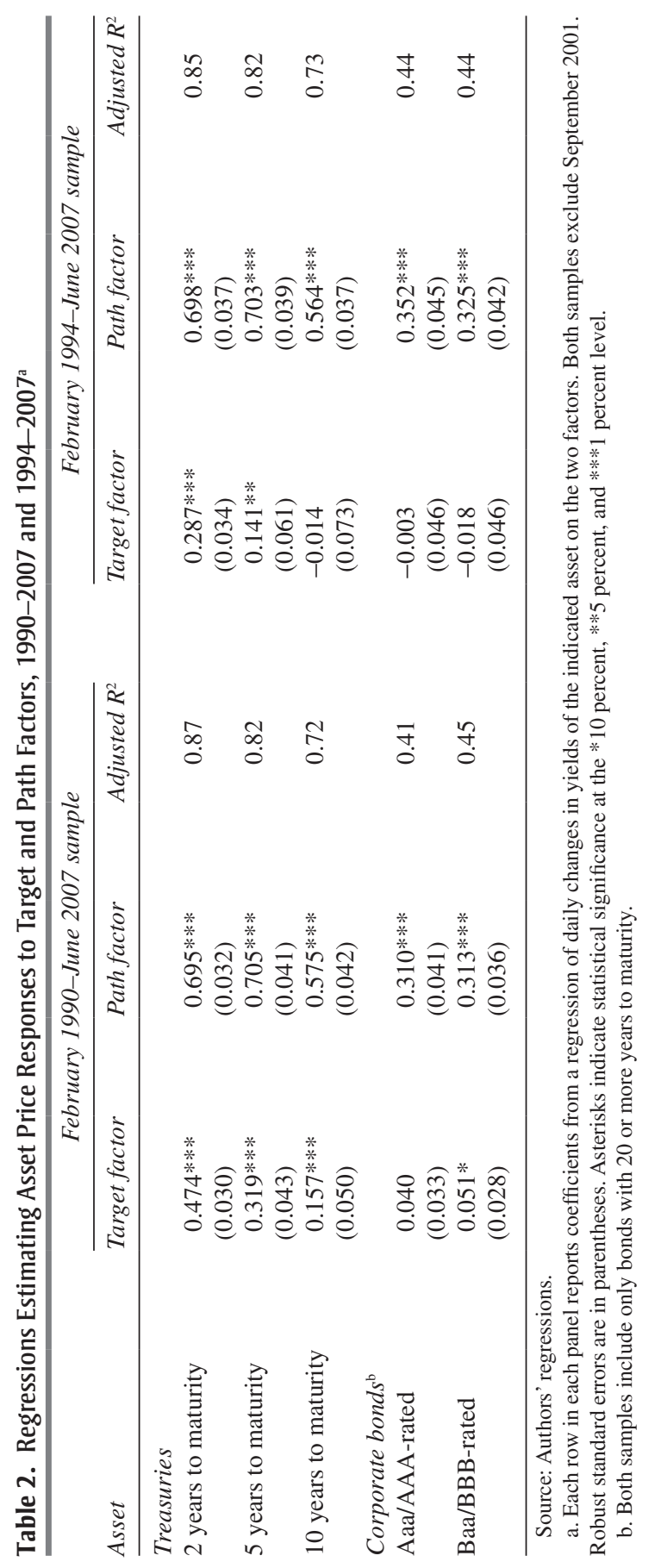


For each month we calculate the revisions to the forecasts of unemployment and CPI inflation for the current and next 3 quarters. Virtually by construction, these are uncorrelated across time. ${ }^{13}$ We then regress these revisions against the identified target and path factors. Table 3 reports the estimates (in basis points per positive 1-bp factor realization) for both precrisis samples. The first notable result is that the $R^{2} \mathrm{~s}$ for these regressions are far lower than those from the analogous asset price regressions in table 2. Since the regressions' residuals account for all macroeconomic news arriving in the month except that in FOMC statements, this low explanatory power is expected.

If surprise FOMC policy announcements represent shocks to the stance of monetary policy unrelated to current macroeconomic circumstances, then a positive innovation to either factor should raise unemployment and lower inflation. Our estimates indicate that the opposite is more typical. For the longer sample, the coefficients on the target factor are statistically significant and negative for unemployment expectations at all four horizons (top panel of table 3). The path factor's coefficients are also all negative, but in only one case is the coefficient statistically significant (at the 10 percent level). Switching to the shorter sample brings the estimates of the target factor's coefficients close to zero and amplifies the negative coefficients on the path factor. Only 3 of the 16 estimated coefficients for inflation (bottom panel) are negative, and none of these are statistically significant. However, the coefficient on the path factor in the current quarter's regression and that on the target factor in the next quarter's regression are significant at the 10 percent and the 5 percent level, respectively, in the later sample.

The counterintuitive signs of the estimates in table 3 require an explanation. The one we favor interprets the GSS forward guidance as Delphic: the public believes that the FOMC has information about macroeconomic fundamentals that the public does not, and that monetary policy surprises arise from this informational advantage. In that case the forecast revision following a positive policy rate innovation encompasses the revelation of unexpectedly strong macroeconomic fundamentals as well as the contractionary effects of the innovation itself.

\section{I.B. Forward Guidance since the Financial Crisis}

The evidence that market participants and professional forecasters are influenced by FOMC forward guidance is suggestive for the current

13. Krane (2011) searches for bias and forecast error predictability in the Blue Chip consensus forecasts for GDP growth and finds none. Similarly, we find no evidence that the Blue Chip forecasts of inflation and unemployment are seriously deficient. 


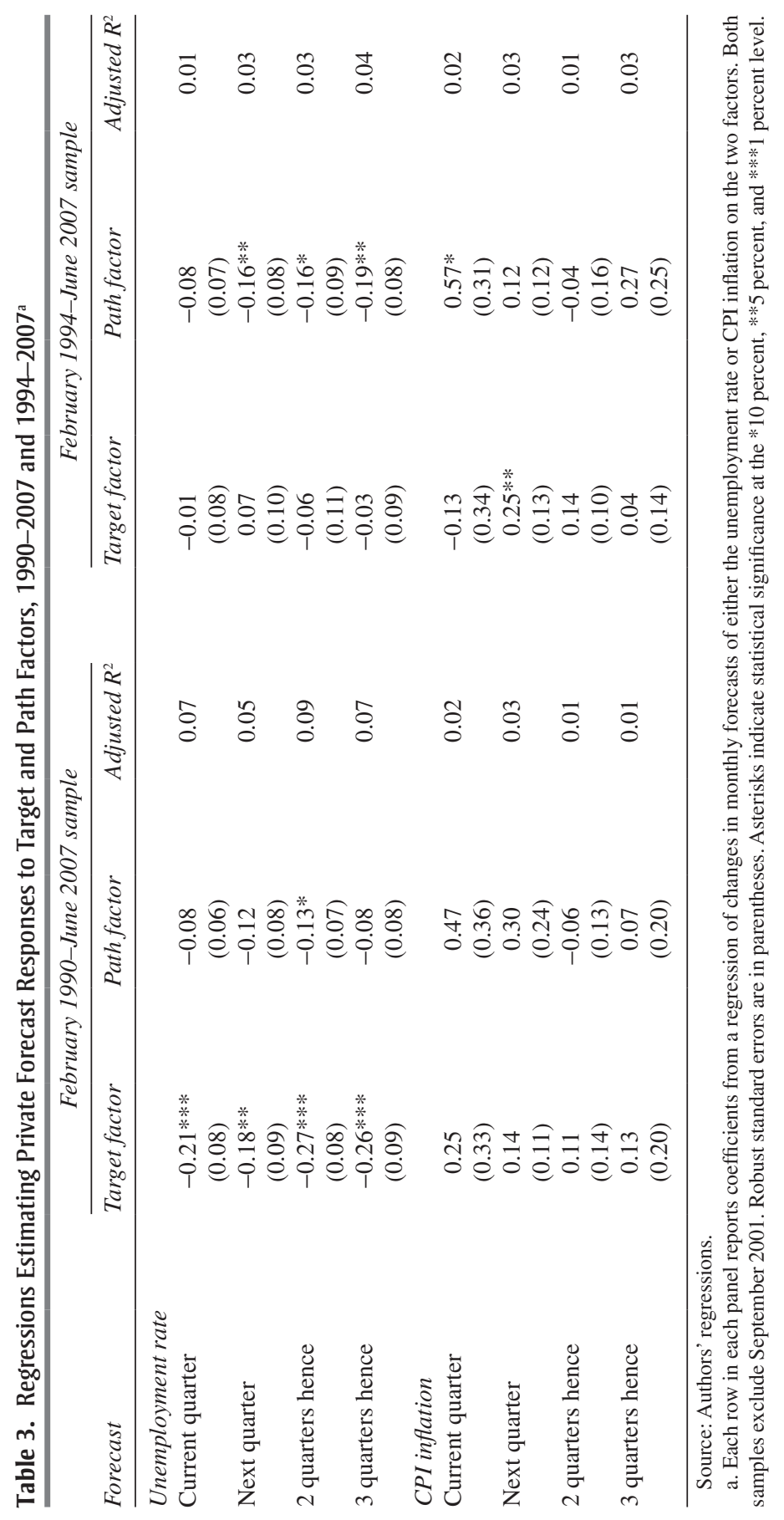


situation, but we hesitate to apply it directly to the present when the ZLB has robbed the FOMC of its principal policy tool. Research on monetary policy announcements since the onset of the crisis has focused almost exclusively on the impact of the FOMC's announcements of large-scale asset purchases (LSAPs). ${ }^{14}$ There is significant evidence that LSAP policies can alter long-term interest rates. For example, Gagnon and others (2010) present an event study of QE1 that documents large reductions in interest rates concurrent with LSAP announcements. Krishnamurthy and Vissing-Jorgensen (2011) evaluate the impact on interest rates of announcements associated with both QE1 and QE2. They uncover several channels through which these announcements have had an impact on asset prices and ascribe a major role to their signaling of lower future federal funds rates. This suggests that one feature of LSAPs resembles forward guidance, and so the findings of Krishnamurthy and VissingJorgensen (2011) can be interpreted as supporting the view that forward guidance has significantly influenced asset prices in the recent period. However, the recent impact of "pure" forward guidance, where the policy action is reflected solely in statement language, remains unclear.

To shed further light on the impact of forward guidance, we apply the GSS methodology to FOMC statements issued since the onset of the financial crisis. Table 4 presents our compilation of relevant statements and the language in each that we judge most pertinent to forward guidance. ${ }^{15}$ The list includes the statements following every scheduled and unscheduled FOMC meeting since August 2007 (39 in all) as well as the November 25, 2008, Board of Governors press release that announced the first stage of QE1. (All LSAP announcements since that press release have been made in postmeeting FOMC statements.) Although several remarks in speeches and testimony by Federal Reserve officials also seem to have been interpreted by markets as forward guidance, we exclude

14. One exception is Wright (2012), who documents the effects of monetary policy surprises on long-term interest rates since the attainment of the ZLB. His analysis draws on identification by heteroskedasticity and does not distinguish between two factors capturing surprises at different horizons over the expected policy path. Swanson and Williams (2012) also discuss the effects of FOMC announcements on long-term yields, but they focus on the responses of medium- and longer-term interest rates to macroeconomic news.

15. We omit the large number of Federal Reserve press releases focused on programs designed to promote the smooth functioning of credit markets because they did not concern the traditional focus of countercyclical monetary policy. 
Table 4. Forward Guidance in Official FOMC Statements, August 2007-December 2011 ${ }^{\text {a }}$

\begin{tabular}{|c|c|c|}
\hline Date of statement & $\begin{array}{l}\text { Federal } \\
\text { funds target } \\
\text { rate }(\%)\end{array}$ & Relevant language \\
\hline August 7, 2007 & 5.25 & $\begin{array}{l}\text { ". . . the Committee's predominant policy concern } \\
\text { remains the risk that inflation will fail to moderate } \\
\text { as expected." }\end{array}$ \\
\hline August 17, 2007 & 5.25 & $\begin{array}{l}\text { ". . the downside risks to growth have increased } \\
\text { appreciably." }\end{array}$ \\
\hline September $18,2007^{\mathrm{b}}$ & 4.75 & $\begin{array}{l}\text { "Developments in financial markets ... have increased } \\
\text { the uncertainty surrounding the economic outlook." }\end{array}$ \\
\hline October 31, 2007 & 4.50 & $\begin{array}{l}\text { ". . the upside risks to inflation roughly balance the } \\
\text { downside risks to growth." }\end{array}$ \\
\hline December 11, 2007 & 4.25 & $\begin{array}{l}\text { "Recent developments ... have increased the uncer- } \\
\text { tainty surrounding the outlook for economic growth } \\
\text { and inflation." }\end{array}$ \\
\hline January $22,2008^{b}$ & 3.50 & "Appreciable downside risks to growth remain." \\
\hline January 30, 2008 & 3.00 & "... downside risks to growth remain." \\
\hline March 18, 2008 & 2.25 & Same as previous \\
\hline April 30, 2008 & 2.00 & $\begin{array}{l}\text { "The substantial easing of monetary policy to date, } \\
\text { combined with ongoing measures to foster market } \\
\text { liquidity, should help to promote moderate growth } \\
\text { over time and to mitigate risks to economic activity." }\end{array}$ \\
\hline June 25, 2008 & 2.00 & $\begin{array}{l}\text { "Although downside risks to growth remain, they ap- } \\
\text { pear to have diminished somewhat, and the } \\
\text { upside risks to inflation and inflation expectations } \\
\text { have increased." }\end{array}$ \\
\hline August 5, 2008 & 2.00 & $\begin{array}{l}\text { "Although downside risks to growth remain, the upside } \\
\text { risks to inflation are also of significant concern to } \\
\text { the Committee." }\end{array}$ \\
\hline September 16, 2008 & 2.00 & $\begin{array}{l}\text { "The downside risks to growth and the upside risks } \\
\text { to inflation are both of significant concern to the } \\
\text { Committee." }\end{array}$ \\
\hline October $8,2008^{b}$ & 1.50 & $\begin{array}{l}\text { "Incoming economic data suggest that the pace of } \\
\text { economic activity has slowed markedly in recent } \\
\text { months. Moreover, the intensification of financial } \\
\text { market turmoil is likely to exert additional restraint } \\
\text { on spending, partly by further reducing the ability of } \\
\text { households and businesses to obtain credit. Inflation } \\
\text { has been high, but the Committee believes that the } \\
\text { decline in energy and other commodity prices and the } \\
\text { weaker prospects for economic activity have reduced } \\
\text { the upside risks to inflation." }\end{array}$ \\
\hline October 29, 2008 & 1.00 & "... downside risks to growth remain." \\
\hline $\begin{array}{l}\text { November } 25,2008^{\mathrm{b}} \\
\quad \text { (press release) }\end{array}$ & $0-0.25$ & $\begin{array}{l}\text { ". . purchases [of } \$ 100 \text { billion of GSEs and } \\
\$ 500 \text { billion of MBSs] are expected to take place } \\
\text { over several quarters." }\end{array}$ \\
\hline
\end{tabular}


Table 4. Forward Guidance in Official FOMC Statements, August 2007-December 2011 ${ }^{\text {a }}$ (Continued)

\begin{tabular}{|c|c|c|}
\hline Date of statement & $\begin{array}{l}\text { Federal } \\
\text { funds target } \\
\text { rate }(\%)\end{array}$ & Relevant language \\
\hline December 16, 2008 & $0-0.25$ & $\begin{array}{l}\text { ". . . the Committee anticipates that weak economic } \\
\text { conditions are likely to warrant exceptionally low } \\
\text { levels of the federal funds rate for some time. The } \\
\text { focus of the Committee's policy going forward will } \\
\text { be to ... stimulate the economy through open market } \\
\text { operations and other measures that sustain the size of } \\
\text { the Federal Reserve's balance sheet at a high level.... } \\
\text { The Committee is also evaluating the potential benefits } \\
\text { of purchasing longer-term Treasury securities." }\end{array}$ \\
\hline January 28, 2009 & $0-0.25$ & $\begin{array}{l}\text { "The Committee continues to anticipate that economic } \\
\text { conditions are likely to warrant exceptionally low } \\
\text { levels of the federal funds rate for some time. The } \\
\text { Committee also is prepared to purchase longer- } \\
\text { term Treasury securities if evolving circumstances } \\
\text { indicate that such transactions would be particularly } \\
\text { effective in improving conditions in private credit } \\
\text { markets." }\end{array}$ \\
\hline $\begin{array}{l}\text { March 18, } 2009 \\
\text { (QE1 announce- } \\
\text { ment) }\end{array}$ & $0-0.25$ & $\begin{array}{l}\text { ". . the Committee will maintain the target range for } \\
\text { the federal funds rate at } 0 \text { to } 1 / 4 \text { percent and anticipates } \\
\text { that economic conditions are likely to warrant excep- } \\
\text { tionally low levels of the federal funds rate for an } \\
\text { extended period. The Committee sees some risk that } \\
\text { inflation could persist for a time below rates that } \\
\text { best foster economic growth and price stability in } \\
\text { the longer term. ... The Committee decided today } \\
\text { to increase the size of the Federal Reserve's balance } \\
\text { sheet further by purchasing up to an additional } \\
\$ 750 \text { billion of [MBSs], bringing its total purchases of } \\
\text { these securities to up to } \$ 1.25 \text { trillion this year, and to } \\
\text { increase its purchases of [GSE] debt this year by up to } \\
\$ 100 \text { billion to a total of up to } \$ 200 \text { billion.... The } \\
\text { Committee decided to purchase up to } \$ 300 \text { billion } \\
\text { of longer-term Treasury securities over the next six } \\
\text { months." }\end{array}$ \\
\hline April 29, 2009 & $0-0.25$ & $\begin{array}{l}\text { ". . Committee sees some risk that inflation could per- } \\
\text { sist for a time below rates that best foster economic } \\
\text { growth and price stability in the longer term. ... } \\
\text { Economic conditions are likely to warrant excep- } \\
\text { tionally low levels of the federal funds rate for an } \\
\text { extended period." }\end{array}$ \\
\hline June 24, 2009 & $0-0.25$ & $\begin{array}{l}\text { ". . economic conditions are likely to warrant excep- } \\
\text { tionally low levels of the federal funds rate for an } \\
\text { extended period.... The Committee expects that } \\
\text { inflation will remain subdued for some time." }\end{array}$ \\
\hline
\end{tabular}

(continued) 


\begin{tabular}{|c|c|c|}
\hline Date of statement & $\begin{array}{l}\text { Federal } \\
\text { funds target } \\
\text { rate }(\%)\end{array}$ & Relevant language \\
\hline August 12, 2009 & $0-0.25$ & $\begin{array}{l}\text { "Although economic activity is likely to remain weak } \\
\text { for a time, the Committee continues to anticipate that } \\
\text { policy actions to stabilize financial markets and institu- } \\
\text { tions, fiscal and monetary stimulus, and market forces } \\
\text { will contribute to a gradual resumption of sustainable } \\
\text { economic growth in a context of price stability. ... } \\
\text { Substantial resource slack is likely to dampen cost } \\
\text { pressures, and the Committee expects that inflation } \\
\text { will remain subdued for some time." }\end{array}$ \\
\hline September 23, 2009 & $0-0.25$ & $\begin{array}{l}\text { “. . economic conditions are likely to warrant excep- } \\
\text { tionally low levels of the federal funds rate for an } \\
\text { extended period. ... [MBS and GSE purchases will } \\
\text { finish by the] end of the first quarter of 2010." }\end{array}$ \\
\hline November 4, 2009 & $0-0.25$ & $\begin{array}{l}\text { “. . economic conditions . . . are likely to warrant } \\
\text { exceptionally low levels of the federal funds rate for } \\
\text { an extended period [and the Committee will com- } \\
\text { plete purchases of GSE debt of about } \$ 175 \text { billion]." }\end{array}$ \\
\hline December 16, 2009 & $0-0.25$ & $\begin{array}{l}\text { ". . economic conditions ... . are likely to warrant } \\
\text { exceptionally low levels of the federal funds rate for } \\
\text { an extended period." }\end{array}$ \\
\hline January 27, 2010 & $0-0.25$ & Same as previous \\
\hline March 16, 2010 & $0-0.25$ & Same as previous \\
\hline April 28, 2010 & $0-0.25$ & Same as previous \\
\hline June 23, 2010 & $0-0.25$ & Same as previous \\
\hline August 10, 2010 & $0-0.25$ & $\begin{array}{l}\text { Same as previous, plus "the Committee will keep con- } \\
\text { stant the Federal Reserve's holdings of securities at } \\
\text { their current level by reinvesting principal payments } \\
\text { from agency debt and agency [MBSs] in longer-term } \\
\text { Treasury securities." }\end{array}$ \\
\hline September 21, 2010 & $0-0.25$ & $\begin{array}{l}\text { Same as June 23, plus "The Committee also will } \\
\text { maintain its existing policy of reinvesting principal } \\
\text { payments from its securities holdings." }\end{array}$ \\
\hline $\begin{array}{l}\text { November 3, } \\
2010 \text { (QE2 } \\
\text { announcement) }\end{array}$ & $0-0.25$ & $\begin{array}{l}\text { Same as previous, plus "In addition, the Committee } \\
\text { intends to purchase a further } \$ 600 \text { billion of longer- } \\
\text { term Treasury securities by the end of the second } \\
\text { quarter of } 2011 . "\end{array}$ \\
\hline December 14, 2010 & $0-0.25$ & Same as previous \\
\hline January 26, 2011 & $0-0.25$ & Same as previous \\
\hline March 15, 2011 & $0-0.25$ & Same as previous \\
\hline April 27, 2011 & $0-0.25$ & Same as previous \\
\hline June 22, 2011 & $0-0.25$ & Same as previous \\
\hline August 9, 2011 & $0-0.25$ & $\begin{array}{l}\text { “. . economic conditions.... are likely to warrant } \\
\text { exceptionally low levels of the federal funds rate at } \\
\text { least through mid-2013." }\end{array}$ \\
\hline September 21, 2011 & $0-0.25$ & Same as previous \\
\hline November 2, 2011 & $0-0.25$ & Same as previous \\
\hline December 13, 2011 & $0-0.25$ & Same as previous \\
\hline
\end{tabular}

Source: Board of Governors of the Federal Reserve System website at www.federalreserve.gov/news events/press/monetary/2012monetary.htm.

a. The November 28, 2008, press release was issued by the Board of Governors of the Federal Reserve System. All other statements were issued by the FOMC. GSE = government-sponsored enterprise; MBS = mortgage-backed security.

b. Statement was issued between regularly scheduled FOMC meetings. 
these from our analysis, since it is difficult to find an objective criterion for including any given instance. ${ }^{16}$

Mimicking our analysis of the precrisis period, we estimate factors from changes in expected future federal funds rates between the close of business the day before and the day of each of the announcements listed in table 4 . Because the horizon over which forward guidance is issued seems to be longer since the crisis than it was during the precrisis period, we examine the behavior of seven futures contracts that pin down the expected path of the federal funds rate over the next year and a half without overlapping: the current-month and 3-month-ahead federal funds futures contracts (again with a scale factor to account for the timing of FOMC meetings within the month) and the 2-, 3-, 4-, 5-, and 6-quarter-ahead Eurodollar futures contracts (again adjusted by the difference between the spot Eurodollar and federal funds rates). As before, we also adjust all rates for an assumed risk premium of 1 bp per month. Just as in the precrisis period, two factors explain most of the variability in the futures data. Henceforth we focus on the first two factors after they have been rotated as in GSS.

Figure 1 is a scatterplot of the path factor against changes in the 10-year Treasury yield for the 40 dates listed in table 4 . We distinguish statements containing announcements of LSAPs from other statements, and the statements most closely associated with QE1 and QE2 (March 18, 2009, and November 3, 2010, respectively) are labeled. The most striking feature of figure 1 is how much of an outlier the March 18, 2009, announcement is. On that date the 10-year yield fell (as intended) $51 \mathrm{bp}$ while the path factor rose $32 \mathrm{bp}$. Markets interpreted the FOMC's announcement as indicating that the recovery would come sooner than previously thought and that, consequently, liftoff in the federal funds rate from the ZLB would come earlier than previously anticipated; the 2-quarter-ahead futures contract rose $60 \mathrm{bp}$ from the day before. In contrast, the response to the QE2 announcement appears very much like the responses to the other FOMC announcements, which indicate a positive relationship between the path factor and changes in the 10-year yield. Indeed, Krishnamurthy and Vissing-Jorgensen (2011, p. 217) find that "the

16. Probably the most relevant instances in this regard are speeches on December 1 , 2008, and August 27, 2010, by Federal Reserve Chairman Ben Bernanke, which were interpreted by markets as opening the door to the first and second round of large-scale purchases of Treasury securities, respectively. With the exception of the December 1, 2008, speech, our compilation includes every QE1 and QE2 date employed in Krishnamurthy and VissingJorgensen's (2011) event study. 
Figure 1. Path Factor and Changes in 10-Year Treasury Yields on FOMC Statement Dates

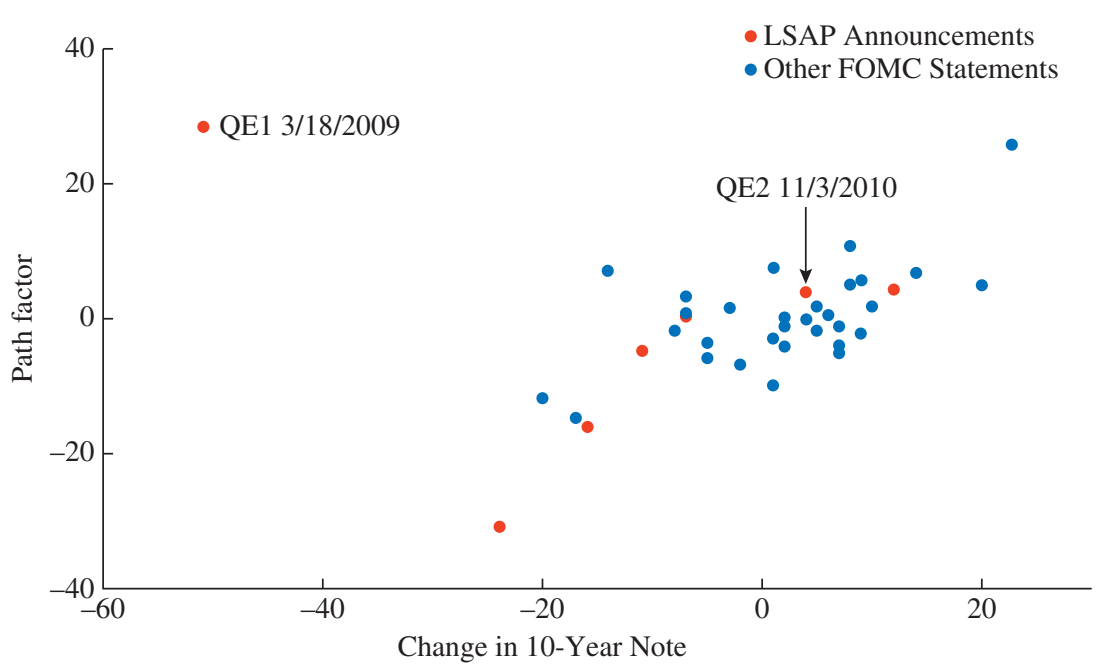

Source: Haver Analytics/Federal Reserve H.15 and authors' calculations based on Chicago Mercantile Exchange data.

main effect on corporate bonds and [mortgage-backed securities] in QE2 appears to have been through a signaling channel, whereby financial markets interpreted QE as signaling lower federal funds rates going forward." The apparently very different response to the March 18, 2009, QE1 announcement motivates us to exclude it from the remainder of our factor analysis.

Table 5 reports the fractions of variance in changes to expected future federal funds rates explained by the target and by the path factor estimated from all the announcements in table 4 except the outlier associated with QE1. The target factor dominates the variation in the current-quarter rate and the 1-, 2-, and 3-quarter-ahead rates, whereas the path factor explains the majority of variation in the three longer rates and negligible shares of the three shortest contracts. This pattern is broadly similar to that for the precrisis period reported in table 1 . The main difference is that here the path factor dominates only those changes in expected interest rates that are 4 or more quarters ahead.

Table 6 reports asset price regression estimates analogous to those of table 2, based on the postcrisis factors. Since this sample is smaller, the estimates' associated standard errors are larger. These estimates strongly 
Table 5. Decomposing the Variance in Changes in Expected Federal Funds Rates, August 2007-December 2011 ${ }^{\mathrm{a}}$

Percent

\begin{tabular}{|c|c|c|}
\hline \multirow[b]{2}{*}{ Federal funds rate futures contract } & \multicolumn{2}{|c|}{$\begin{array}{c}\text { Share of variance due to } \\
\text { indicated factor }\end{array}$} \\
\hline & Target factor & Path factor \\
\hline Current quarter & 94 & 0 \\
\hline Next quarter & 98 & 0 \\
\hline Two quarters hence & 93 & 3 \\
\hline Three quarters hence & 57 & 35 \\
\hline Four quarters hence & 44 & 53 \\
\hline Five quarters hence & 31 & 68 \\
\hline Six quarters hence & 16 & 79 \\
\hline
\end{tabular}

Source: Authors' calculations.

a. Expected interest rates are measured using daily federal funds futures prices and Eurodollar futures prices as described in the text. Numbers do not sum to 100 because the two factors do not explain all the variation in the expected rate changes.

Table 6. Regressions Estimating Asset Price Responses to Target and Path Factors, August 2007-December 2011

\begin{tabular}{lccc}
\hline Asset & Target factor & Path factor & Adjusted $R^{2}$ \\
\hline Treasuries & & & \\
2 years to maturity & $0.592^{* * *}$ & $0.716^{* * *}$ & 0.79 \\
& $(0.096)$ & $(0.160)$ & \\
5 years to maturity & $0.404^{* * *}$ & $0.898^{* * *}$ & 0.66 \\
& $(0.143)$ & $(0.165)$ & \\
10 years to maturity & $0.250^{*}$ & $0.877^{* * *}$ & 0.58 \\
& $(0.131)$ & $(0.103)$ & \\
Corporate bonds & & & $0.631^{* * * *}$ \\
Aaa/AAA-rated & 0.058 & $(0.085)$ & 0.45 \\
& $(0.079)$ & $0.556^{* * *}$ & 0.34 \\
Baa/BBB-rated & 0.065 & $(0.117)$ & \\
& $(0.085)$ & & \\
\hline
\end{tabular}

Source: Authors' regressions.

a. Each row in each panel reports coefficients from a regression of daily changes in yields of the indicated asset on the two factors. Robust standard errors are in parentheses. Asterisks indicate statistical significance at the $* 10$ percent, $* * 5$ percent, and $* * * 1$ percent level.

b. Both samples include only bonds with 20 or more years to maturity.

resemble those from before the crisis. Both factors have a large positive influence on the 2- and 5-year yields, and the path factor substantially influences the 10-year Treasury yield and yields on seasoned Aaa/AAA- and $\mathrm{Baa} / \mathrm{BBB}$-rated corporate bonds. Given the disparity in economic conditions between the pre- and postcrisis sample periods, the similarity of forward guidance effects on asset prices is a striking finding. 
Table 7. Regressions Estimating Private Forecast Responses to Target and Path Factors, August 2007-December 2011

\begin{tabular}{lccc}
\hline Forecast & Target factor & Path factor & Adjusted $R^{2}$ \\
\hline Unemployment rate & & & \\
Current quarter & -0.21 & 0.01 & 0.02 \\
& $(0.19)$ & $(0.31)$ & 0.03 \\
Next quarter & -0.29 & $(0.47)$ & 0.04 \\
& $(0.26)$ & 0.11 & 0.03 \\
2 quarters hence & -0.33 & $(0.62)$ & 0.03 \\
& $(0.34)$ & 0.15 & \\
3 quarters hence & -0.35 & $(0.73)$ & 0.07 \\
& $(0.39)$ & 2.05 & 0.04 \\
CPI inflation & & $(4.17)$ & \\
Current quarter & 1.80 & 0.44 & 0.00 \\
& $(1.82)$ & $(1.43)$ & \\
Next quarter & 0.53 & -0.02 & 0.03 \\
& $(0.64)$ & $(0.27)$ & \\
2 quarters hence & -0.01 & 0.23 & \\
& $(0.12)$ & $(0.29)$ & \\
3 quarters hence & 0.07 & & \\
& $(0.11)$ & & \\
& & &
\end{tabular}

Source: Authors' regressions.

a. Each row in each panel reports coefficients from a regression of changes in monthly forecasts of either the unemployment rate or CPI inflation on the two factors. Robust standard errors are in parentheses.

Table 7 reports estimates for the forecast innovation regressions using the postcrisis data. The estimated standard errors greatly exceed those from the analogous regressions estimated with precrisis data (table 3), so that none of the reported coefficients are statistically significant. Although we conclude that our regression estimates of the effects of forward guidance on macroeconomic expectations since the financial crisis are too imprecise to allow strong quantitative conclusions, the estimates are broadly consistent with those from the precrisis period.

\section{Forward Guidance through an Interest Rate Rule}

The event-study approach used above isolates "pure" forward guidance associated with distinct policy announcements from other monetary policy actions, but it fails to identify any forward guidance communicated through other channels. In this section we present a new and complementary methodology that identifies forward guidance communicated through all the channels available to the FOMC. This approach builds on the long-standing 
practice of summarizing monetary policy with a parsimonious rule for setting the policy rate. By applying such a rule both to actual policy decisions and to observations of private expectations, we are able to identify consensus expectations of how the FOMC will deviate from the monetary policy rule at a specific date in the future.

The empirical implementation of our methodology inserts the Blue Chip forecasts and interest rate futures prices examined above, aggregated to quarterly frequency, into an interest rate rule with two lags of the interest rate and measures of the unemployment gap and inflation. The rule's novelty lies in its residual, which sums components gradually revealed to the public up to 4 quarters before the policy action. The interest rate futures and professional forecasts together are sufficient to identify these forward guidance shocks. For the period 1996Q1 through 2007Q2, the estimated rule describes the 4-quarter-ahead expectation of the interest rate very well: the standard deviation of the 4-quarterahead forward guidance shock is only $9 \mathrm{bp}$. The standard deviation of the interest rate rule's total residual (which sums the forward guidance shocks with a traditional unanticipated policy shock) is $30 \mathrm{bp}$. However, the standard deviation of the anticipated component is $28 \mathrm{bp}$. That is, the Federal Reserve successfully telegraphs most departures from the interest rate rule in advance.

The forward guidance shocks we identify from the interest rate rule differ from the statement date-based shocks of GSS in some ways and resemble them in others. The most notable difference is their factor structure. The contemporaneous policy shock and the four forward guidance shocks revealed every quarter have a single factor that explains most of the 4-quarter-ahead forward guidance but much less at closer horizons. A positive realization of this factor speeds up the usual interest rate changes following a contemporaneous monetary policy shock, so we call it the policy acceleration factor. The FOMC seems to have used this factor heavily during the 2001 recession and in its aftermath. The similarities between GSS-style forward guidance shocks and those measured with an interest rate rule become apparent when we calculate their effects on asset prices and macroeconomic forecasts. Positive forward guidance shocks raise both Treasury and corporate bond yields. By construction, the interest rate rule accounts for the FOMC's typical responses to varying economic fundamentals as measured by inflation and the unemployment gap. Nevertheless, regressions analogous to those in table 3 indicate that the same anticipated deviations from 
this rule affect unemployment and inflation forecasts with the "wrong" sign, just as do the statement date-based GSS shocks. We interpret these results as arising from the FOMC adjusting policy quickly when revisions to macroeconomic expectations catch it "behind the curve."

\section{II.A. Rule-Based Measurement of Forward Guidance}

We consider interest rate rules for the average policy rate over quarter $t$, $r_{t}$, of the following form:

$$
\begin{aligned}
r_{t}= & \mu+\rho_{1} r_{t-1}+\rho_{2} r_{t-2} \\
& +\left(1-\rho_{1}-\rho_{2}\right)\left(\phi_{\pi} \tilde{\pi}_{t}+\phi_{u} \tilde{\mu}_{t}\right)+\sum_{j=0}^{M} v_{t-j, j} .
\end{aligned}
$$

The variables $\tilde{\pi}_{t}$ and $\tilde{u}_{t}$ are the policy-relevant measures of the inflation rate and the unemployment gap (the difference between the unemployment rate and a measure of the economy's non-accelerating-inflation, or "natural," unemployment rate). Parameters $\rho_{1}, \rho_{2}, \phi_{\pi}$, and $\phi_{u}$ determine the degree of interest smoothing and how the policy rate responds to typical changes in macroeconomic conditions.

The distinguishing feature of equation 1 is the last term, which involves the $M+1$ disturbances, $v_{t-j, j}$ for $j=0,1, \ldots, M$. The first of these, $v_{t, 0}$, is the monetary policy disturbance that appears in conventional interest rate rules. It captures the Federal Reserve's response to extraordinary events, such as the September 11 terrorist attacks or the 1997 Asian currency crisis, that warrant a rapid but temporary deviation from the normal policy prescription. The remaining disturbances are forward guidance shocks, because they are revealed to the public before they are applied to the interest rate rule. The public sees $v_{t, j}$ in quarter $t$, and the FOMC applies it to the rule $j$ quarters hence. We gather all of the shocks revealed in quarter $t$ into the vector $\vec{v}_{t} \equiv\left(v_{t, 0}, v_{t, 1}, \ldots, v_{t, M}\right)$. Each realization of $\vec{v}_{t}$ influences the expected path of interest rates. To identify the forward guidance shocks, we wish to map revisions to expectations, which are uncorrelated over time by construction, onto realizations of $\vec{v}_{t}$; so we assume that $\vec{v}_{t}$ is also uncorrelated over time. That is, we assume that the elements of $\vec{v}_{t}$ are news relative to the public information set at the end of $t-1$. For sufficiently large $M$ and under rational expectations, this can be done without loss of generality. ${ }^{17}$ Although $\vec{v}_{t}$ is uncorrelated over time, its elements may be correlated

17. The reason is that a time-series variable at time $t$ always can be decomposed into the sum of its expected value based on information available at $t-1$ and an orthogonal innovation. 
with each other. Allowing for this correlation admits the possibility that the FOMC provides information on multiple future quarters' monetary policy shocks in the same communication.

The practice of including exogenous shocks to the interest rate is commonplace. Our specification differs from conventional interest rate rules only in the assumption that the public observes some of the interest rate shocks before their implementation. The most similar recent work is that of Stefan Laséen and Lars Svensson (2011), who propose modeling forward guidance with an interest rate rule as we do when calculating the equilibrium of a New Keynesian model.

One can recover $\vec{v}_{t}$ using data on private expectations of unemployment, inflation, and the federal funds rate with values of $\rho_{1}, \rho_{2}, \phi_{\pi}$, and $\phi_{y}$ in hand. Here and henceforth, conditional expectations at quarter $t$ are defined in terms of information at the beginning of the quarter. ${ }^{18}$ For any variable $x$, we denote its realization in quarter $t$ with $x_{t}$. Then we use the notation $x_{t}^{j}$ to denote the time $t-j$ conditional expectation of variable $x_{t}$. Since not all variables dated $t$ are known by economic agents at the start of the quarter they are realized, the "nowcast" $x_{t}^{0}$ does not necessarily equal the realized $x_{t}$. For example, $r_{t}^{0}$ is the expectation at the beginning of quarter $t$ of the quarter's average policy rate, which can clearly change over the quarter. If $x$ is not even revealed to the public during the quarter of its realization, then the "backcast" $x_{t}^{-1}$ also might not equal $x_{t}$. The unemployment rate provides a relevant example. Its backcast differs from its realized value because the time taken for its tabulation delays its release.

To measure $\mathrm{V}_{t-M, M}$, suppose that the public expects the FOMC to follow equation 1 on average. Then, taking expectations given information at the start of period $t-M+1$ yields

$$
\begin{aligned}
r_{t}^{M-1}= & \mu+\rho_{1} r_{t-1}^{M-2}+\rho_{2} r_{t-2}^{M-3} \\
& +\left(1-\rho_{1}-\rho_{2}\right)\left(\phi_{\pi} \tilde{\pi}_{t}^{M-1}+\phi_{u} \tilde{u}_{t}^{M-1}\right)+v_{t-M, M} .
\end{aligned}
$$

The residual term in equation 2 equals $v_{t-M, M}$ because the expected value $\mathrm{E}_{t-M+1}\left[\mathrm{v}_{t, j}\right]=0$ for $j=0, \ldots, M-1$. Thus, $v_{t-M, M}$ equals the deviation of the expected interest rate $M-1$ quarters ahead from its value dictated by the interest rate rule's expected value. To recover the other errors, we take

18. This conforms to the timing convention used for the Blue Chip macroeconomic expectations data. 
expectations of equation 1 at two adjacent dates and difference the results. For $0 \leq j<M$ we obtain

$$
\begin{aligned}
& r_{t}^{j-1}-r_{t}^{j}=\rho_{1}\left(r_{t-1}^{j-2}-r_{t-1}^{j-1}\right)+\rho_{2}\left(r_{t-2}^{j-3}-r_{t-2}^{j-2}\right) \\
& \quad+\left(1-\rho_{1}-\rho_{2}\right)\left[\phi_{\pi}\left(\tilde{\pi}_{t}^{j-1}-\tilde{\pi}_{t}^{j}\right)+\phi_{u}\left(\tilde{u}_{t}^{j-1}-\tilde{u}_{t}^{j}\right)\right]+v_{i-j, j} .
\end{aligned}
$$

Equation 3 shows that $v_{t-j, j}$ equals the change within quarter $t-j$ in the expected interest rate for quarter $t$ corrected for the change in the interest rate rule's expected value arising from revisions in private expectations of inflation and unemployment. This disturbance embodies expected deviations from "typical" monetary policy. Forward guidance influences $v_{t-j, j}$ when the FOMC communicates a prospective change in its shortrun policy goals with or without a credible Odyssean commitment. The anticipated residuals might also arise from external factors omitted from the rule, but only to the extent that they affect the policy rate through channels other than the forecasts of the unemployment gap and inflation that already appear in the rule. How much weight is given to a conditioning variable when constructing a forecast depends on the prevailing economic conditions. For example, before the increase in foreign trade associated with globalization, there was less need to pay attention to foreign inflation and the exchange rate than there is today. This does not necessarily mean that the policy rule incorrectly omits foreign inflation or the exchange rate, because these variables are an input into agents' forecasts.

\section{II.B. Estimation}

Implementing this methodology requires observations of private expectations and the estimation of $\mu, \rho_{1}, \rho_{2}, \phi_{\pi}$, and $\phi_{u}$. The Blue Chip consensus forecasts give us $u_{t-1}^{-1}$ and $\pi_{t-1}^{-1}$ (backcasts), $u_{t}^{0}$ and $\pi_{t}^{0}$ (nowcasts), and $u_{t+j}^{j}$ and $\pi_{t+j}^{j}$ for $j=1, \ldots, 4$ (forecasts). In March and October, Blue Chip survey participants report forecasts of each variable's average value 7 to 11 years after the current calendar year. We use the most recently published consensus long-run forecast for the unemployment rate as a measure of each quarter's natural rate of unemployment, $u_{t}^{*}$. From this we construct the expected unemployment gap in quarter $t+j$ as $\hat{u}_{t}^{j} \equiv u_{t}^{j}-u_{t}^{*}$. Our Blue Chip data contain observations for the period 1989Q2 through 2011Q4.

Our implementation of the interest rate rule employs averages of the expected unemployment gap and expected inflation over the previous, cur- 
rent, and next quarters as perceived at the beginning of the next quarter. That is:

$$
\begin{aligned}
& \tilde{u}_{t}=\frac{1}{3} \sum_{j=-1}^{1} \hat{u}_{t+j}^{j-1} \\
& \tilde{\pi}_{t}=\frac{1}{3} \sum_{j=-1}^{1} \pi_{t+j}^{j-1} .
\end{aligned}
$$

Here we have abused our notation by supposing that $\tilde{u}_{t}$ and $\tilde{\pi}_{t}$ are realized at the end of quarter $t$ even though they depend on information available "at the beginning" of quarter $t+1$. We can construct forecasts of $\tilde{u}_{t}$ and $\tilde{\pi}_{t}$ from the Blue Chip data up to 3 quarters ahead, so we set $M$ in equation 1 equal to 4 . That is, we assume that the process of communicating forward guidance begins 4 quarters before the policy decision in question.

Although the Blue Chip data contain forecasts of the federal funds rate, we prefer to base our measures of expected interest rates on the futures market prices used in section I from each quarter's final trading day. Our estimation uses only data from the period in which federal funds futures have been actively traded in large volume, which James Hamilton and others (2011) identify as beginning sometime in 1994. Because the estimation requires lags, we begin our sample with the forecasts of interest rates that prevailed in 1996Q1. ${ }^{19}$ These prices give us the interest rates that our procedure requires when $M$ equals $4: r_{t}^{0}, r_{t}^{1}, \ldots, r_{t}^{5}$. The other observations required to calculate $\vec{v}_{t}$ are $\tilde{u}_{t}^{0}, \ldots, \tilde{u}_{t}^{3}$ and $\tilde{\pi}_{t}^{0}, \ldots, \tilde{\pi}_{t}^{3}$. We can calculate these with the backcast, nowcast, and four quarterly forecasts in the Blue Chip data.

One frequent approach to estimating the parameters of an interest rate rule simply assumes that the autoregressive terms in equation 1 sufficiently capture the interest rate's serial correlation, so that the policy shock is serially uncorrelated and ordinary least squares estimation can be employed. This assumption fails if past forward guidance influences the unemployment gap and inflation, so we require an alternative estimator. We turn to a generalized

19. Beginning the sample in 1996Q1 also excludes an outlying observation from the Eurodollar futures market in 1994Q4 from our analysis. In that quarter the Eurodollar rate for delivery in 1995Q4 (averaged across that quarter's months) rose from 6.7 percent to 8.0 percent. However, it had returned to 6.5 percent by the end of 1995Q1. Such large changes in expected future interest rates were common in the early 1990s but occurred much less frequently in our sample period. 
method of moments (GMM) implementation of an instrumental variables strategy. From the Blue Chip data we can calculate $\hat{u}_{t}^{M}$ and $\pi_{t}^{M}$. These, $r_{t-2}^{M-2}$, and $r_{t-1}^{M-1}$ are valid instruments for $v_{t 0}, v_{t-1,1}, \ldots, v_{t-M, M}$ because those monetary policy shocks are all revealed after the beginning of quarter $t-M$. Therefore, we can construct a valid GMM estimator based on the population moment conditions

$$
\mathrm{E}\left[g_{t}(\gamma) \otimes Z_{t}\right]=0
$$

Here, $\gamma=\left(\mu, \rho_{1}, \rho_{2}, \phi_{\pi}, \phi_{u}\right)$ is the parameter vector, $g_{t}(\cdot)$ is a function that takes the parameter values and returns the vector $\left(v_{t 0}, v_{t-1}, 1, \ldots, v_{t-M, M}\right)$, and $Z_{t}=\left(\hat{u}_{t}^{M}, \pi_{t}^{M}, r_{t-2}^{M-2}, r_{t-1}^{M-1}\right)$ is the vector of instruments. With $M=4$, this provides 16 moment restrictions to estimate 4 parameters.

This moment condition underlying our GMM estimator depends on the assumption that our interest rate rule omits no relevant information known in quarter $t-M$. This assumption would be violated if the FOMC gave forward guidance more than 4 quarters in advance. In that case the value of $v_{t, 4}$ inferred using the interest rate rule's correct parameter values should be correlated with the instruments in $Z_{t}$. The "considerable period" language provides one obvious potential example of such long-term forward guidance. The relevant part of the August 12, 2003, statement that introduced it reads

The Committee judges that, on balance, the risk of inflation becoming undesirably low is likely to be the predominant concern for the foreseeable future. In these circumstances, the Committee believes that policy accommodation can be maintained for a considerable period.

The statement's emphasis on anticipated inflation leads us to read this as Delphic rather than Odyssean, so we expect it to have operated through the interest rate rule rather than through its residuals. We can think of no other concrete examples of long-term forward guidance of any sort during our sample period, so we believe any biases from choosing $M$ to conform with the Blue Chip forecast horizon to be small. ${ }^{20}$

As noted above, our estimation sample begins in 1996Q1. We consider the crisis period that arguably began in 2007Q3 to be unique, and

20. A violation of our moment condition could also arise from mismeasurement of private expectations. If the Blue Chip survey measures equal the public's true expectations summed with a classical measurement error, then the measurement errors contribute to $g(\gamma)$. This biases our GMM estimator only to the extent that the same errors influence the measured values of $\hat{u}_{t}^{4}$ and $\pi_{t}^{4}$ in $Z_{t}$. 
so we end our estimation sample with 2007Q2. The estimated interest rate rule is

$$
\begin{aligned}
r_{t}= & -0.05+1.60 \times r_{t-1}-0.66 \times r_{t-2} \\
& (0.02)(0.02)) \\
& -(1-0.94) \times \underset{(0.28)}{1.10} \tilde{u}_{t}+(1-0.94) \\
& \times 2.32 \pi_{t}+\sum_{j=0}^{4} v_{t-j, j} .
\end{aligned}
$$

Heteroskedasticity- and autocorrelation-consistent standard errors appear below each estimate in parentheses. The estimates' associated $J$ statistic is very small $(0.25)$, so the estimates clearly pass the test of overidentifying restrictions.

Two features of the interest rate rule are worth noting. First, we find an important role for second-order autoregressive dynamics. This gives the interest rate's response to a one-time innovation (holding $\tilde{u}_{t}$ and $\tilde{\pi}_{t}$ fixed) a hump shape: monetary policy adjustments start small, grow, and persist. Second, the estimated rule satisfies the Taylor principle that the long-run interest rate rises more than one for one with a persistent increase in inflation. The standard error on this coefficient is small enough to comfortably exclude the possibility that this arises only from sampling error.

\section{II.C. How Well Does the Public Forecast Deviations from the Interest Rate Rule?}

Given the estimated parameter values, we follow the procedure presented above to recover the history of $\vec{v}_{t}$ from the available data. The standard deviations of the forward guidance shocks by horizon are 12, 20, 13, 11 , and $9 \mathrm{bp}$ for $\mathrm{v}_{t, 0}$ through $\mathrm{v}_{t, 4}$, respectively. As noted above, the fact that the 4-quarter-ahead forward guidance shock $v_{t, 4}$ has such a small standard deviation suggests that the estimated rule summarizes medium-run expectations of the federal funds rate very well. We can use these estimates to calculate a variance decomposition of the interest rate rule's intercept. ${ }^{21}$ Overall, it appears that the FOMC communicates about 40 percent of the monetary policy variance in the quarter before its realization and another 40 percent in the 1 to 3 quarters before then.

21. Although the elements of $\vec{v}_{t}$ are correlated with each other, we assume that its realizations are independent over time. Therefore, the five shocks contributing to the interest rate rule's intercept in a given quarter are mutually independent. 
Figure 2. The Interest Rate Rule's Residual and Its Forward Guidance Component, 1996-2007

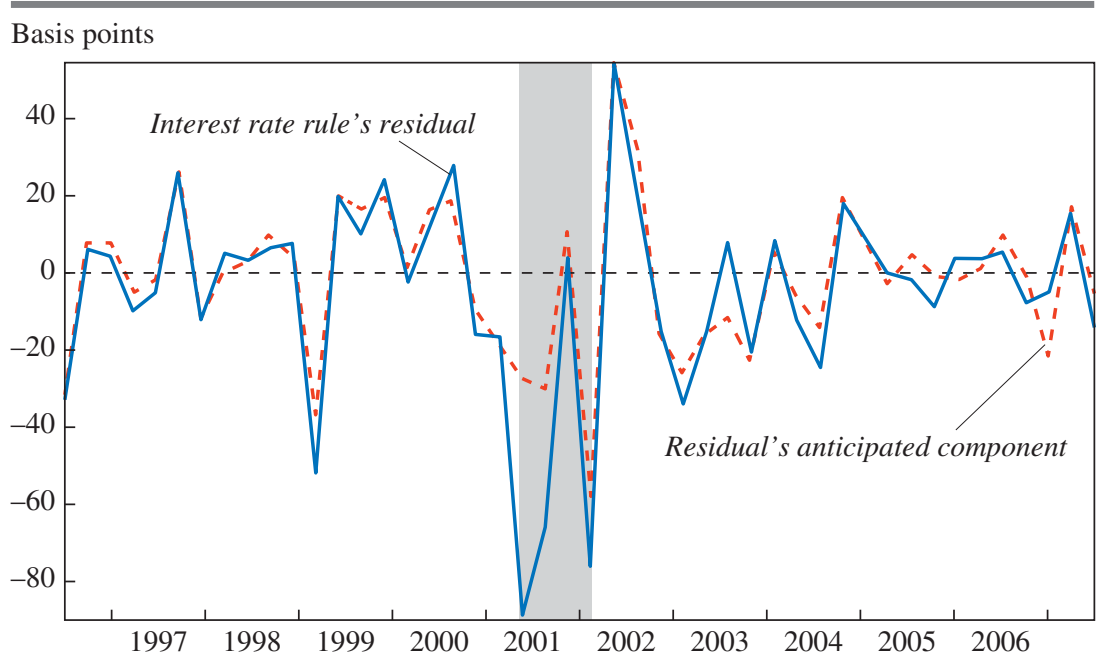

Source: Authors' calculations.

a. Shading indicates the 2001 recession.

Figure 2 gives a visual perspective on this decomposition. It plots the composite residual for the interest rate rule $\sum_{j=0}^{4} v_{t-j, j}$ as well as its forward guidance component, which simply drops the contemporaneous shock $v_{t, 0}$. Overall, the two series track each other quite closely. Indeed, their sample correlation is 0.9. At the onset of the 2001 recession, however, the two series differ by $62 \mathrm{bp}$, reflecting the well-known sudden reversal of the monetary policy stance at that date. In the second quarter of 2001, the difference is $37 \mathrm{bp}$. Two events that do not show up with particularly large values of $v_{t, 0}$ are the Asian financial crisis and September 11. The estimate of $V_{199703,0}$ is only $-0.8 \mathrm{bp}$. It turns out that markets anticipated during the previous quarter most of the monetary policy accommodation provided in that quarter. Following September 11, the FOMC increased accommodation only in 2001Q4, because the Federal Reserve concentrated on maintaining the orderly functioning of financial markets in the final weeks of 2001Q3. Nevertheless, market participants anticipated this move, so it shows up in $\mathrm{v}_{2001 \mathrm{Q}, 1}$, estimated at $-85 \mathrm{bp}$.

Since each realization of $\vec{v}_{t}$ moves the entire expected path of interest rates, it is reasonable to suppose that its elements correlate with each other. Indeed, such correlation underlies the factor analysis of GSS. The sample correlation matrix is as follows: 


$\begin{array}{ccccc} & v_{t, 0} & v_{t, 1} & v_{t, 2} & v_{t, 3} \\ v_{t, 1} & 0.02 & & & \\ v_{t, 2} & -0.05 & 0.22 & & \\ v_{t, 3} & -0.32 & 0.03 & -0.17 & \\ v_{t, 4} & -0.32 & -0.26 & 0.22 & 0.16\end{array}$

The fact that $v_{t, 0}$ is negatively correlated with both $v_{t, 3}$ and $v_{t, 4}$ suggests that the public expects some "last-minute" monetary policy adjustments to be reversed in the relatively near future. The other forward guidance shocks are uncorrelated with $v_{t, 0}$, and they display relatively low correlations with each other.

\section{II.D. Factor Analysis}

Although the correlations among the five shocks contributing to the interest rate rule's intercept are not large, GSS's successful use of factor analysis motivates us to investigate how a factor model explains them. The negative correlations of $v_{t, 0}$ with $v_{t, 3}$ and $v_{t, 4}$ hint at a single factor structure in which the factor "tilts" the monetary policy shocks, providing accommodation today while promising to take it away later. We investigate this impression by estimating

$$
\vec{v}_{t}=\Lambda f_{t}+e_{t}
$$

Here $\Lambda$ is a $5 \times 1$ matrix of factor loadings, $f_{t}$ is a scalar factor with a mean of zero and variance of 1 , and $e_{t}$ is a $5 \times 1$ vector of mutually independent "idiosyncratic" errors.

The maximum-likelihood estimates of the factor loadings from this model are $5,6,4,-3$, and -7 basis points for $v_{t, 0}$ through $v_{t, 4}$, respectively. These estimates reveal that the factor does indeed tilt the path of monetary accommodation: a 1-standard-deviation negative realization lowers the interest rate rule's intercept by about $5 \mathrm{bp}$ for each of the next 3 quarters and increases it by about the same amount for the following 2 quarters. The factor model's remaining parameters describe the standard deviations of the idiosyncratic errors in $e_{t}$. These estimates-11, 19, 13, 10, and 6 for $v_{t, 0}$ through $v_{t, 4}$, respectively-show that the factor accounts for about 15 percent of the variance of $v_{t, 0}$, about 10 percent of the variance of $v_{t, 1}$, $v_{t, 2}$, and $v_{t, 3}$, and about 60 percent of the variance of $v_{t, 4}$. That is, the factor 
Figure 3. Direct Effects of Monetary Policy Shocks on the Interest Rate

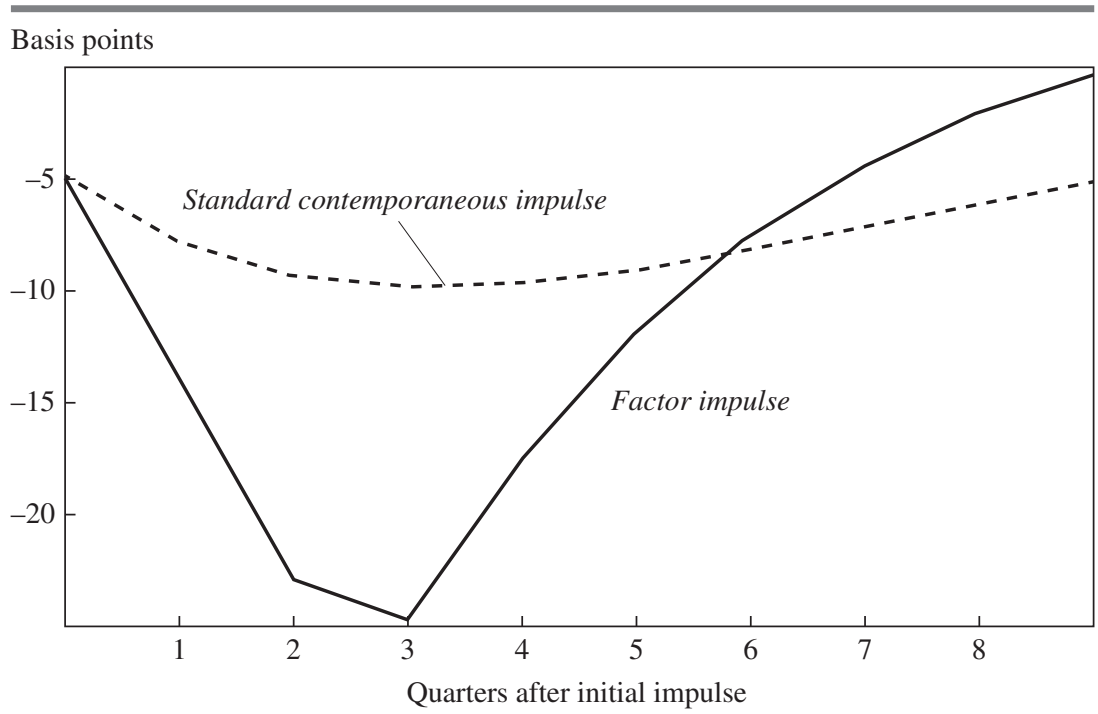

Source: Authors' calculations.

accounts for most of 4-quarter-ahead forward guidance but leaves most forward guidance issued at shorter horizons unexplained.

Figure 3 plots the direct interest rate effects (that is, omitting any possible endogenous responses of inflation or unemployment) over 9 quarters of a 1-standard-deviation shock to the factor. For comparison, we also plot the response to a standard contemporaneous impulse that initially lowers the interest rate by the same amount $(5 \mathrm{bp})$. As dictated by the secondorder autoregressive parameters, the interest rate falls for 3 quarters after the standard contemporaneous impulse and then begins a slow rise back to its mean. The interest rate also falls for 3 quarters following the factor shock, but it falls much more relative to the initial response. Thereafter the impulse's effects dissipate quickly: after 9 quarters the interest rate has returned to its mean. To us, these responses suggest labeling this factor "policy acceleration." When the factor equals zero, policy adjustments proceed at their normal pace. A negative realization increases the speed of the interest rate's decline and recovery, whereas positive realizations increase the speed of impact of contractionary policy.

Figure 4 plots over time the identified policy acceleration factor scaled by its impact on the current interest rate. This measure achieved its maximum value of 9 bp in 1999Q2, although its value in the next quarter almost 
Figure 4. Estimated Policy Acceleration Factor, 1996-2007

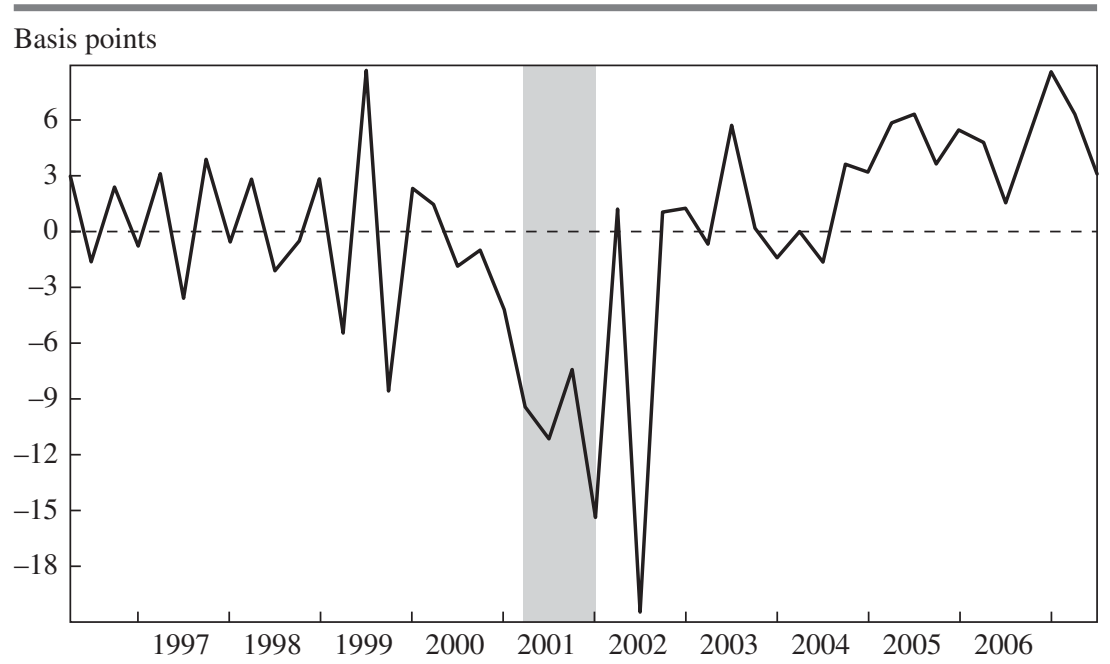

Source: Authors' calculations.

a. Shading indicates the 2001 recession.

exactly offset this promised accelerated stimulus. Its minimum of $-21 \mathrm{bp}$ occurred in the wake of the 2001 recession, in 2002Q2. In that quarter the 1-, 2-, and 3-quarter-ahead forecasts of the unemployment rate all rose $30 \mathrm{bp}$. (For a point of comparison, these revisions' sample standard errors are 17, 20, and $21 \mathrm{bp}$, respectively.) Its other large and negative realizations occurred during the 2001 recession itself, when the upward unemployment forecast revisions were even larger. It appears that the FOMC successfully signaled its intention to accelerate accommodation following adverse unemployment news in 2001 and 2002.

\section{II.E. Asset Price and Forecast Responses to Forward Guidance Shocks Identified from an Interest Rate Rule}

One clear virtue of the GSS path factor is its documented impacts on asset prices that are relevant for private decisions. We now examine the impact on asset prices of the forward guidance shocks identified from the interest rate rule by regressing the same financial variables used in table 2 on them. Since our data are quarterly, we measure bond yields and the stock market index on the quarter's final trading day. The changes in these from the previous quarter are our dependent variables. For independent variables we use a constant and all five of the $v$ shocks. Table 8 reports the estimated 
Table 8. Regressions Estimating Asset Price Responses to Forward Guidance Shocks Identified from an Interest Rate Rule, 1996Q1-2007Q2a

\begin{tabular}{|c|c|c|c|c|c|c|c|}
\hline \multirow[b]{2}{*}{ Asset } & \multirow[b]{2}{*}{ Constant } & \multicolumn{5}{|c|}{ Shock } & \multirow{2}{*}{$\begin{array}{c}\text { Adjusted } \\
R_{2}\end{array}$} \\
\hline & & $v_{t, 0}$ & $v_{t, 1}$ & $v_{t, 2}$ & $v_{t, 3}$ & $v_{t, 4}$ & \\
\hline \multicolumn{8}{|l|}{ Treasuries } \\
\hline 2 years to maturity & $\begin{array}{c}5.90 \\
(4.47)\end{array}$ & $\begin{array}{l}1.08 * * * \\
(0.37)\end{array}$ & $\begin{array}{l}1.98 * * * \\
(0.22)\end{array}$ & $\begin{array}{l}1.56^{* * * *} \\
(0.33)\end{array}$ & $\begin{array}{c}0.70 * \\
(0.42)\end{array}$ & $\begin{array}{c}0.89^{*} \\
(0.50)\end{array}$ & 0.77 \\
\hline 5 years to maturity & $\begin{array}{c}3.46 \\
(4.31)\end{array}$ & $\begin{array}{c}0.61 * \\
(0.36)\end{array}$ & $\begin{array}{l}1.83 * * * \\
(0.21)\end{array}$ & $\begin{array}{l}1.91 * * * \\
(0.32)\end{array}$ & $\begin{array}{l}1.43 * * * \\
(0.40)\end{array}$ & $\begin{array}{l}1.25 * * \\
(0.49)\end{array}$ & 0.78 \\
\hline 10 years to maturity & $\begin{array}{c}1.57 \\
(4.44)\end{array}$ & $\begin{array}{c}0.38 \\
(0.37)\end{array}$ & $\begin{array}{l}1.48 * * * \\
(0.22)\end{array}$ & $\begin{array}{l}1.60 * * * \\
(0.33)\end{array}$ & $\begin{array}{l}1.41 * * * \\
(0.42)\end{array}$ & $\begin{array}{l}1.29 * * * \\
(0.50)\end{array}$ & 0.70 \\
\hline \multicolumn{8}{|l|}{ Corporate bonds ${ }^{\mathrm{b}}$} \\
\hline Aaa/AAA-rated & $\begin{array}{c}0.60 \\
(4.63)\end{array}$ & $\begin{array}{c}0.19 \\
(0.38)\end{array}$ & $\begin{array}{l}0.65 * * * \\
(0.23)\end{array}$ & $\begin{array}{l}0.75^{* *} \\
(0.34)\end{array}$ & $\begin{array}{l}0.86^{* *} \\
(0.43)\end{array}$ & $\begin{array}{c}0.17 \\
(0.52)\end{array}$ & 0.33 \\
\hline Baa/BBB-rated & $\begin{array}{c}0.57 \\
(4.01)\end{array}$ & $\begin{array}{c}0.13 \\
(0.33)\end{array}$ & $\begin{array}{l}0.69 * * * \\
(0.20)\end{array}$ & $\begin{array}{l}0.71 * * \\
(0.30)\end{array}$ & $\begin{array}{l}1.00 * * * \\
(0.38)\end{array}$ & $\begin{array}{c}0.37 \\
(0.45)\end{array}$ & 0.42 \\
\hline
\end{tabular}

Source: Authors' regressions.

a. Each row reports coefficients from a regression of changes in yields of the indicated asset from the last trading day of a quarter to that of the next on a constant and on shocks $v_{t, 0}$ through $v_{t, 4}$, where $v_{t, 0}$ is the monetary policy shock that occurs contemporaneously with announcement $t$, and the remaining shocks $\mathrm{V}_{t, j}$ are forward guidance shocks indicating the change in monetary policy announced at $t$ to occur in quarter $j$. The regression coefficients can be interpreted as the response (in basis points) of the indicated asset price to a 1-basis-point change in the indicated $v_{t, j}$. Standard errors are in parentheses. Asterisks indicate statistical significance at the $* 10$ percent, $* * 5$ percent, and $* * * 1$ percent level.

b. Both samples include only bonds with 20 or more years to maturity.

coefficients, their standard errors, and the regressions' $R^{2} \mathrm{~s}$. We express all of the variables in bp, so the coefficients can be read as the response in basis points to a 1-bp change in the right-hand-side variable.

Although the coefficients' standard errors are not small, the regression estimates clearly show that the identified forward guidance shocks are associated with substantial changes in asset prices. A 100-bp increase in $v_{t, 1}$ raises the 2- and 5-year Treasury yields by almost $200 \mathrm{bp}$ and the 10 -year Treasury yield by about $150 \mathrm{bp}$. The effects on the two corporate bonds are more modest, 65 and $69 \mathrm{bp}$. In light of the standard errors, we judge the estimated effects of $v_{t, 2}$ and $v_{t, 3}$ on these bond yields to be about the same. The relatively small variance of $v_{t, 4}$ translates into relatively large standard errors for its estimated effects on bond yields. Nevertheless, the point estimates for the effects of $v_{t, 4}$ are statistically significant for the 5and 10-year Treasury yields. Overall, the estimated asset price effects of forward guidance inferred from the interest rate rule are much larger than the corresponding effects of forward guidance identified from the GSS event-study methodology. 
Table 9. Regressions Estimating Forecast Revisions in Response to Forward Guidance Identified from an Interest Rate Rule, 1996Q1-2007Q2a

\begin{tabular}{|c|c|c|c|c|c|c|c|}
\hline \multirow[b]{2}{*}{ Change in forecast ${ }^{\mathrm{b}}$} & \multirow[b]{2}{*}{ Constant } & \multicolumn{5}{|c|}{ Shock } & \multirow{2}{*}{$\begin{array}{c}\text { Adjusted } \\
R_{2}\end{array}$} \\
\hline & & $\mathrm{V}_{t, 0}$ & $v_{t, 1}$ & $V_{t, 2}$ & $v_{t, 3}$ & $\mathrm{~V}_{t, 4}$ & \\
\hline \multicolumn{8}{|l|}{ Unemployment rate } \\
\hline$u_{t}^{-1}-u_{t}^{0}$ & $\begin{array}{l}-6.82 * * * \\
(2.47)\end{array}$ & $\begin{array}{c}-0.37 * \\
(0.20)\end{array}$ & $\begin{array}{c}-0.20 \\
(0.12)\end{array}$ & $\begin{array}{c}-0.13 \\
(0.18)\end{array}$ & $\begin{array}{l}-0.38 \\
(0.23)\end{array}$ & $\begin{array}{c}0.46 \\
(0.28)\end{array}$ & 0.28 \\
\hline$u_{t+1}^{0}-u_{t+1}^{1}$ & $\begin{array}{c}-4.02 \\
(2.92)\end{array}$ & $\begin{array}{c}-0.34 \\
(0.24)\end{array}$ & $\begin{array}{c}-0.30 * * \\
(0.14)\end{array}$ & $\begin{array}{c}-0.05 \\
(0.22)\end{array}$ & $\begin{array}{c}-0.27 \\
(0.27)\end{array}$ & $\begin{array}{c}0.54 \\
(0.33)\end{array}$ & 0.27 \\
\hline$u_{t+2}^{1}-u_{t+2}^{2}$ & $\begin{array}{c}-3.39 \\
(2.93)\end{array}$ & $\begin{array}{c}-0.46^{*} \\
(0.24)\end{array}$ & $\begin{array}{c}-0.47 \text { *** } \\
(0.14)\end{array}$ & $\begin{array}{c}-0.02 \\
(0.22)\end{array}$ & $\begin{array}{l}-0.20 \\
(0.27)\end{array}$ & $\begin{array}{c}0.30 \\
(0.33)\end{array}$ & 0.34 \\
\hline$u_{t+3}^{2}-u_{t+3}^{3}$ & $\begin{array}{c}-2.86 \\
(2.65)\end{array}$ & $\begin{array}{c}-0.31 \\
(0.22)\end{array}$ & $\begin{array}{l}-0.47 * * * \\
(0.13)\end{array}$ & $\begin{array}{c}-0.00 \\
(0.20)\end{array}$ & $\begin{array}{c}-0.07 \\
(0.25)\end{array}$ & $\begin{array}{c}0.26 \\
(0.30)\end{array}$ & 0.34 \\
\hline \multicolumn{8}{|l|}{ Inflation } \\
\hline$\pi_{t}^{-1}-\pi_{t}^{0}$ & $\begin{array}{c}1.83 \\
(5.55)\end{array}$ & $\begin{array}{c}-0.35 \\
(0.46)\end{array}$ & $\begin{array}{c}0.23 \\
(0.27)\end{array}$ & $\begin{array}{c}-0.08 \\
(0.41)\end{array}$ & $\begin{array}{c}-0.61 \\
(0.52)\end{array}$ & $\begin{array}{c}-0.09 \\
(0.63)\end{array}$ & 0.05 \\
\hline$\pi_{t+1}^{0}-\pi_{t+1}^{1}$ & $\begin{array}{c}-5.20 * \\
(2.91)\end{array}$ & $\begin{array}{c}-0.18 \\
(0.24)\end{array}$ & $\begin{array}{c}0.17 \\
(0.14)\end{array}$ & $\begin{array}{c}0.05 \\
(0.21)\end{array}$ & $\begin{array}{c}-0.44 \\
(0.27)\end{array}$ & $\begin{array}{c}0.07 \\
(0.33)\end{array}$ & 0.10 \\
\hline$\pi_{t+2}^{1}-\pi_{t+2}^{2}$ & $\begin{array}{l}-7.55^{* * * *} \\
(2.69)\end{array}$ & $\begin{array}{c}-0.05 \\
(0.22)\end{array}$ & $\begin{array}{c}0.15 \\
(0.13)\end{array}$ & $\begin{array}{c}0.11 \\
(0.20)\end{array}$ & $\begin{array}{c}0.35 \\
(0.25)\end{array}$ & $\begin{array}{c}-0.02 \\
(0.30)\end{array}$ & 0.10 \\
\hline$\pi_{t+3}^{2}-\pi_{t+3}^{3}$ & $\begin{array}{l}-5.32 * * \\
(2.11)\end{array}$ & $\begin{array}{c}-0.25 \\
(0.18)\end{array}$ & $\begin{array}{c}0.18 * \\
(0.10)\end{array}$ & $\begin{array}{c}-0.07 \\
(0.16)\end{array}$ & $\begin{array}{c}0.09 \\
(0.20)\end{array}$ & $\begin{array}{c}-0.04 \\
(0.24)\end{array}$ & 0.14 \\
\hline
\end{tabular}

Source: Authors' regressions.

a. Each row reports coefficients from a regression of quarterly revisions to forecasts of the unemployment gap or CPI inflation on a constant and on shocks $v_{t, 0}$ through $v_{t, 4}$, where $v_{t, 0}$ is the monetary policy shock that occurs contemporaneously with announcement $t$, and the remaining shocks $v_{t, j}$ are forward guidance shocks indicating the change in monetary policy announced at $t$ to occur in quarter $j$. Standard errors are in parentheses. Asterisks indicate statistical significance at the $* 10$ percent, $* * 5$ percent, and $* * * 1$ percent level.

b. Each forecast revision is expressed as the forecast value for the period $t+j$ outcome made at time $t+j-n$ minus the same forecast value made at time $t+j-n-1$, where $t+j$ is the subscript and $n$ and $n+1$ are the superscripts.

We find one aspect of the results in table 8 puzzling: the forward guidance shocks have much larger estimated effects on bond yields than does the contemporaneous monetary policy shock, but the only substantial difference between $v_{t, j}$ and $v_{t, 0}$ is a $j$-quarter implementation delay. If the Treasury rates correspond to the appropriate average of expected shortterm rates plus a term premium, and the forward guidance affects only the expected short-term rates, then the responses should be nearly identical. The fact that they are not strongly suggests that our identified forward guidance shocks are affecting term premiums. Fully exploring this intriguing result lies beyond the scope of the present paper.

Table 9 reports the results from regressing the eight forecast revisions against a constant and the five v's. With rational expectations, the constant 
term should be irrelevant. It is indeed so for three of the four unemployment forecast revisions, but the Blue Chip forecasters consistently made a small (but statistically significant) 7-bp error in their final unemployment forecast. We see similar small but systematic errors in inflation expectations. The slope coefficients' standard errors are quite large (on the order of 20 to $30 \mathrm{bp}$ ), but nevertheless many of the coefficients on $v_{t, 1}$ in the unemployment regressions are negative and statistically significant. That is, promises of more-restrictive policy in the next quarter are associated with reductions in unemployment expectations. Although the analogous coefficients from the inflation regressions are not statistically significant, it is also worth noting that they are positive.

Of course, the New Keynesian model requires that reductions to current and future interest rates be unanticipated if they are to lower expected unemployment and raise expected inflation, so the negative reaction of unemployment to $v_{t, 1}$ clearly cannot be interpreted as the direct macroeconomic effect of unanticipated forward guidance. However, neither can it be interpreted as reflecting simple reverse causality from publicly known macroeconomic circumstances to monetary policy, because the interest rate rule accounts for typical monetary policy choices given expectations of unemployment and inflation. One possibility worth considering is that the effects arise because the FOMC systematically responds to recent revisions in expectations.

To understand this further, consider the following augmented interest rate rule:

$$
\begin{aligned}
r_{t}= & \mu+\rho_{1} r_{t-1}+\rho_{2} r_{t-2}+\left(1-\rho_{1}-\rho_{2}\right)\left(\phi_{\pi} \tilde{\pi}_{t}+\phi_{u} \tilde{u}_{t}\right) \\
& +\eta\left(\tilde{u}_{t}-\tilde{u}_{t}^{L}\right)+\sum_{j=0}^{M} v_{t-j, j} .
\end{aligned}
$$

Here $\eta<0$ measures the extent to which the FOMC reacts to unemployment news received over the last $L$ quarters, specified here as $\tilde{u}_{t}-\widetilde{u}_{t}^{L}$. One might suppose that $\eta$ will be large and negative if the FOMC becomes systematically worried about falling behind the curve following unemployment surprises. If $L \leq M$, then the newly added term in equation 4 is orthogonal to the instruments we used for estimation, so its presence will not affect our estimates of $\rho_{1}, \rho_{2}, \phi_{\pi}$, and $\phi_{u}$. However, it will change the inferred values of the interest rate rule's expected intercept, and through this will influence the estimated v's. Under this interpretation of the results in table 9, the FOMC's actions are history dependent. The estimated interest rate rule 
states the typical policy stance given economic conditions forecasted 4 quarters in advance, but the FOMC would respond more aggressively to the same set of circumstances if it forecasted them only shortly before their arrival. $^{22}$

\section{II.F. Summary}

What does the analysis of forward guidance identified from a standard interest rate rule tell us? First, and perhaps most important for the potential viability of forward guidance-based strategies today, the public and the FOMC together have extensive experience with the communication of relatively short term forward guidance. Indeed, the FOMC used forward guidance to signal its acceleration of accommodation in late 2001 and early 2002. Overall, the public anticipated about 40 percent of the variance in the interest rate rule's disturbance 3 or 4 quarters in advance. Second, unanticipated accommodative forward guidance reduces the interest rates relevant for households' and firms' economic decisions. That is, it seems possible for the FOMC to influence longer-term interest rates that are outside of its direct control by communicating its intention to lower the short-term policy rate persistently.

\section{Using Odyssean Forward Guidance}

The foregoing analysis suggests that the FOMC has experience successfully communicating its intended future behavior in response to prevailing macroeconomic conditions. We interpret this to mean that communication difficulties do not present an insurmountable barrier to monetary policies based on Odyssean forward guidance, and that therefore it is worth considering the practical consequences of adopting such policies. Currently, the FOMC has an extraordinary degree of forward guidance in place with its "late 2014" statement language. In this section we investigate the consequences of interpreting that language as Odyssean forward guidance that implements the policy recommendations of Eggertsson and Woodford (2003) and others. There are legitimate concerns that forward guidance

22. We cannot estimate coefficients like $\eta$ in equation 4 by regressing the measured values of $\vec{v}_{t}$ on expectations revisions, because the true values of $\vec{v}_{t}$ should be endogenously correlated with the expectations revision. Since the expectations revision is uncorrelated over time virtually by construction, neither can we employ an instrumental variables estimator with lagged information as instruments. This leads us to believe that the cross-equation restrictions of structural models will be essential for identification and estimation of the real effects of forward guidance. 
of this kind places the FOMC's mandated price stability goal at risk. We consider these by forecasting the path of the economy under the present forward guidance and subjecting that forecast to two upside risks: higher inflation expectations and faster deleveraging by households and firms. We undertake this analysis using the medium-scale DSGE model developed at the Federal Reserve Bank of Chicago for just such a purpose.

Evans (2011) has proposed conditioning the FOMC's forward guidance on outcomes of unemployment and inflation expectations. Under his proposal, the FOMC would announce specific conditions under which it will begin lifting its policy rate above zero: either unemployment falling below 7 percent or medium-term expected annual inflation rising above 3 percent would trigger liftoff from the ZLB. Bright-line threshold rules such as these are designed to maintain low interest rates even as the economy begins expanding on its own (as prescribed by Eggertsson and Woodford 2003) while providing safeguards against unexpected developments that might put the FOMC's price stability goal in jeopardy. We illustrate that such conditioning, if credible, could be helpful in limiting the inflationary consequences of an unexpectedly early end to the postcrisis deleveraging.

Our conclusions obviously depend on the assumed structure of the model economy and the values we assign its parameters. One might therefore doubt the usefulness of our model-based experiments, since there is little consensus on what the "right" structural model is, and even when there is agreement on the model, there is often disagreement over its parameter values. Nevertheless, we believe our experiments are both interesting and relevant to policy, for at least two reasons. First, the model is very similar to other widely used models and is essentially the standard structural tool for monetary policy analysis in the United States and around the world. Second, the model's parameters are estimated using a rich array of macroeconomic data so that our analysis has a firm empirical grounding.

We begin by briefly describing the model, its estimation, and how we calibrate it to the current policy environment. Then we present our baseline forecast and the consequences for monetary policy of two alternative scenarios.

\section{III.A. The Model}

The model is adapted from Justiniano and others (2011) and thus closely resembles many other medium-scale empirical New Keynesian models. ${ }^{23} \mathrm{~A}$ single representative household owns all firms and supplies the economy's

23. The model is described in more detail in Brave and others (2012). 
labor. Final goods are produced with differentiated intermediate goods, which themselves are produced with capital and differentiated labor. The intermediate goods market and the labor market are monopolistically competitive. Prices of both kinds of differentiated inputs are sticky and are subject to partial indexation. ${ }^{24}$ Hence standard forward-looking Phillips curves connect wage and price inflation with the marginal rates of substitution between consumption and leisure and marginal cost, respectively. Other frictions include endogenous capacity utilization, costs of adjusting investment growth, and internal habit preferences, where "internal habit" refers to diminishing current utility in lagged own consumption. The combination of all these features is very close to that in models by Lawrence Christiano, Martin Eichenbaum, and Evans (2005), Frank Smets and Rafael Wouters (2007), and many others, so that knowledge of these models is sufficient for understanding the results.

The model has one feature that distinguishes it from other New Keynesian frameworks: the monetary policy interest rate rule. ${ }^{25}$ This rule is given by equation 1 , except that we set $\rho_{2}=0$ and replace $\tilde{u}_{t}$ with the policy-relevant output gap, $\tilde{y}_{t}{ }^{26}$ The policy-relevant measure of inflation in equation 1 is defined by

$$
\tilde{\pi}_{t}=\frac{1}{4} \sum_{j=-1}^{2} \mathrm{E}_{t} \hat{\pi}_{t+j}-\hat{\pi}_{t}^{*}
$$

where "^" denotes deviation from steady state. Equation 5 says that policyrelevant inflation is the deviation of a 4-quarter average of inflation from the time-varying inflation anchor $\hat{\pi}^{*}$. The model's inflation anchor varies exogenously and follows an AR(1) process. It is included to account for low-frequency movements in inflation and to consider policy experiments in which inflation expectations become "unanchored." The 4-quarter moving average of inflation includes both lagged, current, and future values of inflation. The monetary authority uses the structure of the model to forecast the future terms.

24. In each period wages and prices have a constant probability of being optimally reset; otherwise they are exogenously indexed to a convex combination of steady-state inflation, last period's inflation, and (for wages) productivity growth.

25. The model and estimation involve other unique features, but these do not change the model's shock propagation mechanisms, which continue to resemble those in other mediumscale New Keynesian models. The model includes a financial accelerator as in Gilchrist, Ortiz, and Zakrajšek (2011), but this ends up being unimportant for the results.

26. In future work we intend to consider the case where $\rho_{2} \neq 0$. 
We define the output gap as

$$
\begin{gathered}
\tilde{y}_{t}=\frac{1}{4} \sum_{j=-1}^{2} \mathrm{E}_{t} \hat{x}_{t+j}, \\
\mathrm{E}_{t}\left\{\left[1+\lambda(1-L)^{2}(1-F)^{2}\right] \hat{x}_{t}\right\}=\mathrm{E}_{t}\left[\lambda(1-L)^{2}(1-F)^{2} \hat{y}_{t}\right]
\end{gathered}
$$

where $L$ and $F$ denote lags and leads, respectively, and $\lambda$ is a smoothing parameter. Equation 6 defines the output gap as a 4-quarter moving average of detrended model output. Following Vasco Cúrdia and others (2011), the monetary authority detrends output using the filter given by equation 7 . (We consider only stationary solutions.) This detrending approximates Hodrick-Prescott filtering. The moving average of filtered output has the same lead-lag structure as inflation and so also includes forward-looking terms, which embody news about inflation and the output gap up to 2 quarters ahead.

We use the GSS factor structure for the forward guidance shocks in equation 1. In particular, we allow there to be a target factor and a path factor driving forward guidance, both of which are independent and identically distributed over time. All current and forward guidance shocks load onto the target factor, and all but the contemporaneous policy shock load onto the path factor. Corresponding to each current and forward guidance shock there is also an additive idiosyncratic shock. For the precrisis sample we set $M=4$ in equation 1 and estimate the factor loadings, the two factor variances, and variances for the idiosyncratic shocks at each horizon of forward guidance. Agents in the model therefore see a credible commitment to deviate from the typical response of policy to current economic conditions going out 4 quarters. Within the context of the model, the forward guidance shocks are entirely Odyssean because they are a (credible) commitment to a future action.

We identify the contemporaneous, forward guidance, and inflation anchor shocks using data on the federal funds rate, federal funds rate futures prices, and long-run (10-year) inflation expectations taken from the Survey of Professional Forecasters. The current policy shock moves the current rate more than it does future rates, whereas the forward guidance and the inflation anchor shocks move expected future federal funds rates more than they do the current rate. This difference is a key source of identification. 
Both the inflation anchor and the forward guidance shocks influence inflation, with the effects of the latter arising through the Phillips curve. We assume that the inflation anchor is very persistent, so that the effects of forward guidance shocks on inflation expectations are comparatively more concentrated at shorter horizons. As a result, the forward guidance shocks are identified from changes in future rates that are larger than changes in the current rate and are associated with only small movements in long-run inflation expectations. We do not use the Blue Chip data to identify forward guidance in the model because we want to consider horizons of forward guidance beyond 1 year during the period in which the ZLB is binding.

A natural objection to using forward guidance as a tool for generating additional monetary accommodation is that, by doing so, the monetary authority risks inflation expectations becoming unhinged. In our sample, inflation expectations exhibit a downward trend, so we strongly suspect that episodes of forward guidance raising long-run inflation expectations are absent from our precrisis sample. That said, one needs to be wary of this possibility in the current environment.

In addition to the monetary policy shocks, the model's fluctuations are driven by eight "structural" shocks. With one exception noted below, these shocks are assumed to follow an AR(1) process. Four of these shocks move real GDP and inflation (as measured by the GDP deflator) in the same direction on impact, so we refer to these as demand shocks. One, the discount shock, changes households' rate of time discounting. Another two are financial disturbances: the spread shock generates fluctuations in the external finance premium beyond the level warranted by current economic conditions, and the net worth shock generates exogenous fluctuations in private balance sheets. ${ }^{27}$ The fourth demand shock, called the government shock, is a shock to the sum of government spending, net exports, and the change in valuation of inventories. Four other shocks move real GDP and inflation in opposite directions on impact, and so we call these supply shocks. These shocks directly change neutral technology, investmentspecific technology, markups of intermediate goods prices, and households' disutility from labor. The last of these is assumed to follow an $\operatorname{ARMA}(1,1)$ process, to parsimoniously address low-frequency dynamics in hours worked and high-frequency variation in hourly wages. Other shocks that

27. These shocks enter because of the financial accelerator mentioned earlier. The net worth shock plays a negligible role in fluctuations, but the spread shock is a major driver of fluctuations. The model propagates the spread shock essentially as it does a shock to the marginal efficiency of investment identified using spread data. 
are of small importance in accounting for the data are shocks that do not affect agents' decisions: idiosyncratic shocks to the various price measures used in estimation, and measurement error in the two financial variables described below. ${ }^{28}$

\section{III.B. Estimation}

We use a two-step procedure to assign values to our DSGE model's parameters. First, we estimate the model over the period from 1989Q2 (when federal funds futures contract data begin) to 2007Q2 (just before the onset of the financial crisis) under the assumption that forward guidance extends out 4 quarters. Second, for the period 2007Q3-2011Q4 we fix the non-forward guidance parameters at their estimated values (with four exceptions highlighted below) and reestimate forward guidance under the assumption that it extends out 10 quarters. Our policy experiments are based on this new set of monetary policy parameters, but the model's determination of the state of the economy takes into account the data from before 2007Q4 as well as the parameter values that were in force at that time.

Our estimates for the period 1989Q2-2007Q2 imply that most fluctuations are driven by the demand shocks. ${ }^{29}$ The data used to estimate the model include growth rates of nominal GDP per capita, consumption, and investment; hours per capita worked in the nonfarm business sector; nominal compensation per hour worked in nonfarm business; the GDP deflator; the deflators corresponding to model-based measures of consumption and investment; the core personal consumption expenditures (PCE) deflator; core CPI; 10-year-ahead forecasts of CPI; an interest rate spread; the ratio of private credit to GDP; the federal funds rate; and contemporaneous expectations of the federal funds rate 1 to 4 quarters hence. Consumption is measured as consumption of nondurable goods and services, and investment includes business fixed investment, residential investment, and PCE on durable goods. ${ }^{30}$ The interest rate spread is a weighted average of high-

28. Model-consistent measures of consumption prices do not correspond well with either of the measures commonly referenced by policymakers and market participants, core PCE and core CPI. We use a factor structure to model three consumption price series: the two popular core measures and the measure designed to be consistent with the model. Doing this delivers predictions for core PCE and core CPI and limits the structural impact of highfrequency fluctuations in inflation that are likely driven by measurement error. Model-based inflation is identified with the common factor.

29. Technical details of the estimation are discussed in Brave and others (2012).

30. The remaining components of aggregate expenditures—government spending, net exports, and private inventory accumulation-are modeled as the government shock. 
yield corporate and mortgage-backed bond spreads over 10-year Treasuries and an asset-backed bond spread over 5-year Treasuries, where the weights equal the shares of nonfinancial business, household mortgage, and household consumer debt in a measure of total private credit that includes both households' and nonfinancial businesses' debts.

Brave and others (2012) report the parameter estimates in more detail. Here we highlight two sets of parameters that have important implications for the outcomes of the policy experiments. First, the monetary policy rule displays a high degree of interest rate smoothing, the inflation gap coefficient obeys the Taylor principle, and the output gap coefficient is smaller than the coefficient for inflation. Reflecting the downward trend in inflation over our sample, the inflation anchor is very persistent. The plausibility of the policy rule depends in part on the nature of the output gap in the rule. Brave and others (2012) demonstrate that the model's output gap corresponds well to the gap published by the Congressional Budget Office.

Second, the estimated model has large nominal and real rigidities. Partly because of the sample over which it is estimated, the slope of the price Phillips curve is very small, about an order of magnitude smaller than single-equation estimates (for example, those of Galí and Gertler 1999 and Eichenbaum and Fisher 2007). The wage Phillips curve slope is also small but more in line with estimates that do not rely on the full structure of the model, such as those by Argia Sbordone (2006). Our estimates imply that there is limited feedback from aggregate activity to wage or price inflation in the model. The estimated real rigidities as implied by the elasticity of capacity utilization, investment adjustment costs, and habit are similar in magnitude to other estimates in the literature (for example, Justiniano and others 2011) and impart considerable inertia in response to shocks.

\section{III.C. Policy Experiments}

The macroeconomic outcomes from 2007Q3 to 2011Q4 are unusual compared with those of the period used to estimate the model. Therefore, to conduct policy experiments relevant to the current economic environment, we calibrate some of the model's parameters and reestimate the effects of forward guidance. This reestimation is particularly important because of the relatively long horizon over which forward guidance has been issued by the FOMC during the recent period.

We calibrate three parameters for the period 2007Q3-2011Q4: the persistence of the discount shock, the variance of the inflation anchor shock, and the coefficient on the output gap in the policy rule. To capture the idea 
that deleveraging by households and firms following the financial crisis is unusually slow, we raise the persistence of the discount shock from its estimated value in the precrisis sample. ${ }^{31}$ Consequently, the model sees discount shocks playing a larger role since 2007Q2 than at other times, leading to much lower aggregate demand at the end of the sample. Essentially the model interprets much of the weakness in the data as reflecting agents' desires to save much more than they have at other times under similar conditions. We set the variance of the inflation anchor innovation to one-fourth its estimated value from the precrisis period. This choice is motivated by the fact that inflation expectations exhibit a downward trend in the first part of our sample but have fluctuated considerably less since then. Finally, we assume a coefficient on the output gap in the model's policy rule that is three times the size of the precrisis estimate. Our motivation here is that the FOMC's policy response to a very large recession may be more aggressive than to a modest one. Together these assumptions increase the likelihood that the ZLB is binding in any given quarter since 2007Q3.

Given the calibrated parameters and precrisis estimates for the remaining parameters excluding forward guidance and the discount shock's variance, we reestimate the factor loadings, factor variances, and idiosyncratic variances that characterize forward guidance as well as the discount shocks' variance over the period 2007Q3-2011Q4 under the assumption that forward guidance extends out 10 quarters. ${ }^{32}$ Our estimation of forward guidance in this period uses expected future federal funds rates going out 10 quarters from each date in the sample. With estimates in hand and data for this period, the Kalman smoother is used to back out the model's interpretation of the shocks hitting the economy since the crisis and their implications for the model's state variables as of 2011Q4. One important implication of our calibration and estimated forward guidance is that the model sees the ZLB as binding from 2008Q4 until the end of our sample in 2011Q4. ${ }^{33}$ At this last date the model can be used to generate a forecast under the assumption that no further shocks hit the economy. This is our baseline forecast.

31. The discount factor is commonly used to model episodes in which the ZLB is binding. See, for example, Christiano and others (2011).

32. We reestimate the discount shock's variance to ameliorate concerns that we have imposed excessive weight on this shock in explaining the crisis.

33. We say the ZLB is binding at any given date if, when all but the forward guidance factor shocks have been fed into the model to generate a conditional forecast beginning in 2008Q3, the forecasted path of the federal funds rate at each date would be below zero for at least one period at short horizons. 
Figure 5. Baseline and Alternative Projections

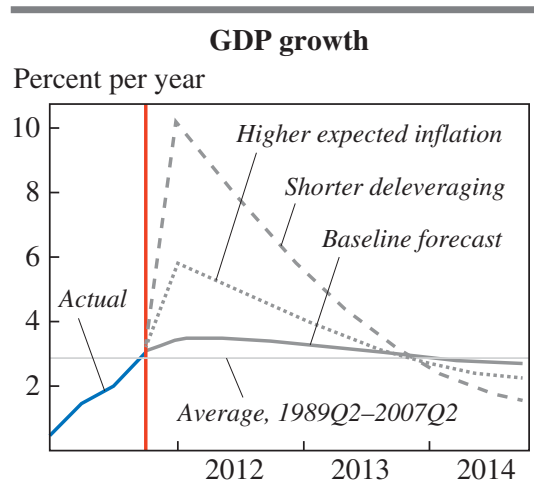

Federal funds rate

Percent per year

Percent per year

Core PCE inflation

Percent per year
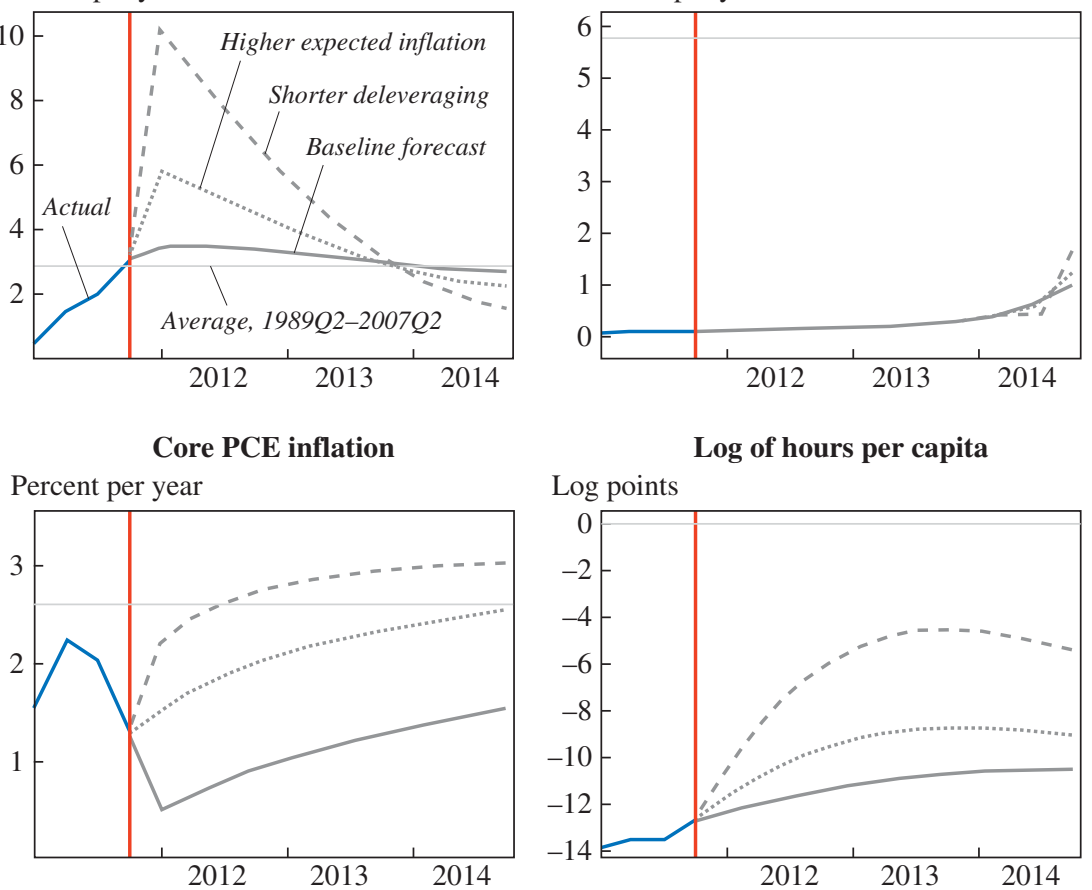

Log of hours per capita

Log points

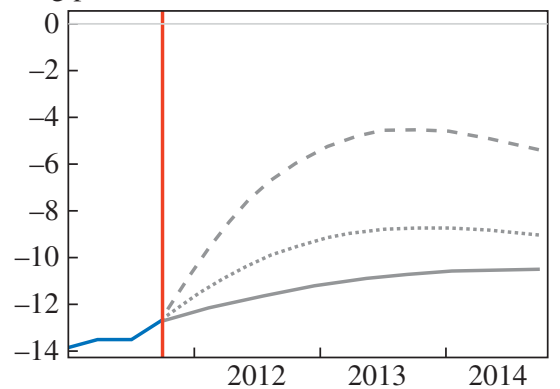

Source: Authors' calculations.

Figure 5 displays the baseline forecast along with forecasts corresponding to two alternative scenarios described below. The horizontal line in each plot indicates the long-run average of the variable in question over the sample 1989Q2-2007Q2 (the logarithm of hours per capita has a mean that is very close to zero). The forward guidance in the baseline forecasts has been estimated to fit the federal funds rate futures path through mid-2014, after which the model predicts a mild liftoff in the funds rate to about 1 percent at the end of 2014. This path is roughly in line with the "late 2014" forward guidance in the January and March 2012 FOMC statements. Corresponding to this path for the funds rate, the baseline forecast calls for growth slightly above trend for 2012, returning to trend in 2013 and 2014. Growth is sufficiently tepid that the log of hours per capita is still $10 \log$ points below its steady-state level by the end of the forecast horizon. Core PCE inflation, after initially dropping, is forecasted to rise slowly toward its long-run average. 
Figure 6. Inflation and Unemployment in the Baseline Forecast

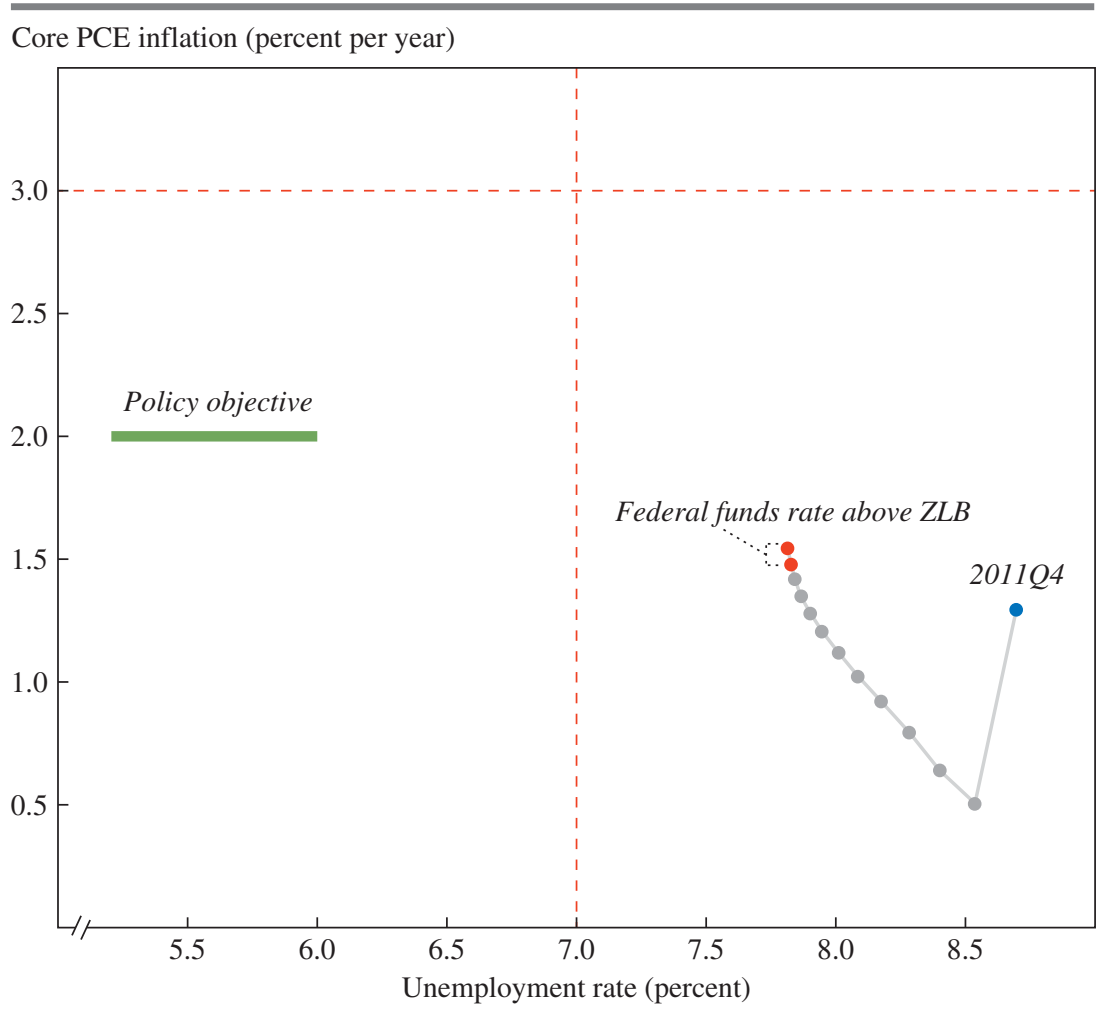

Source: Projections of the authors' model described in the text.

Figure 6 shows the baseline forecast in inflation-unemployment space. ${ }^{34}$ The horizontal bar represents the FOMC's policy objective of 2 percent annual inflation, as described in the FOMC document "Longer-Run Goals and Policy Strategy," and the "central tendency" of longer-run unemployment of 5.2 to 6.0 percent reported in the January 2012 release of FOMC participants' economic projections. The 2011Q4 launch date for the forecast is labeled, with the economy's path proceeding from there. The smaller dots along the path indicate the period of a near-zero federal funds rate, and the two dots at the far end of the path indicate forecast dates where the

34. Our model does not have unemployment in it. However, an ordinary least squares regression of unemployment on hours per capita fits extremely well. We use this regression model to map our forecast for hours per capita into a forecast for unemployment. 
federal funds rate has risen above the ZLB. The bright-line thresholds of 7 percent unemployment and 3 percent inflation are also shown.

In this baseline forecast, core inflation has moved closer to the FOMC's explicit objective by the end of 2014. However, unemployment at that date seems high relative to any rate that would be consistent with the FOMC's mandated goal of maximum sustainable employment. Lengthening the period that the federal funds rate is kept at zero would bring policy closer to the optimum identified by Eggertsson and Woodford (2003) and Werning (2012). The FOMC may be disinclined to push the limit of monetary policy accommodation very far in this dimension, however. Although calendardate communications may have an Odyssean component, most market analysis seems to interpret the dates as Delphic communications, possibly limiting their stimulating effect. Finding acceptable bright-line thresholds might impart a larger commitment to accommodation. Since the forecast does not breach either the unemployment or the inflation threshold in this baseline scenario, the threshold rule would prescribe keeping the funds rate low for a longer period.

It is worth emphasizing that beyond providing additional Odyssean forward guidance, such a threshold rule offers a risk management approach to guarding against unforeseen circumstances. To illustrate this point, we consider two experiments that simulate the effects of developments that give rise to greater inflation concerns. In each case we calculate the model's forecast from 2011Q4 onward under the assumption that an unanticipated event occurs in 2012Q1. The state of the economy in 2011Q4 includes all prior realizations of forward guidance, and agents in the model foresee exceptionally low interest rates through to late 2014. Our scenarios evaluate the consequences of maintaining this policy regardless of developments that could lead the FOMC to start raising the federal funds rate earlier. We do not impose the threshold policy in either scenario. Rather, we simply monitor the boundaries to examine whether such conditional forward guidance would call for a liftoff from the ZLB sooner than currently anticipated.

For each scenario we assume either a permanent change in a single model parameter or the realization of a shock for one period. In the scenario with a parameter change, we resolve the model and use this solution for the associated forecast. In both scenarios we compute the forecast starting from the same estimated state of the economy used to construct the baseline forecast. In the scenario with a sudden increase in long-run inflation expectations, the unanticipated event is an unusually large and persistent innovation to the inflation anchor. We assume a single innovation to the inflation anchor that generates an immediate increase in long-run inflation 
expectations of 1 percentage point. ${ }^{35}$ In the rapid deleveraging scenario, we assume that the persistence of the discount rate shock drops from its calibrated level of 0.95 to its precrisis level of 0.75 but do not consider any additional shocks. In this scenario, past realizations of the discount shock die out much sooner than anticipated in the baseline forecast (the half-life of a discount shock declines from 3.4 years to 2.4 quarters.)

Each scenario involves solving for the forward guidance that reproduces the expected funds path through 2014Q2. This is accomplished by setting one of the idiosyncratic shocks to zero and then solving for the realization of the target and path factors in the first period, plus the other nine idiosyncratic shocks such that the funds path is matched exactly through 2014Q2. (We apply the estimated factor loadings underlying the baseline forecast to calculate the forward guidance shocks.) As figure 5 illustrates, both alternative scenarios generate fast growth immediately: faster deleveraging occurs through a less contractionary discount factor, and higher expected inflation through lower real interest rates. Therefore, maintaining the funds rate path requires very large expansionary realizations of the path factor-essentially large expansionary forward guidance. With this large amount of monetary accommodation in place, annual inflation rises above 2 percent in both scenarios, although hours per capita remain relatively low. Presumably less expansionary monetary policy, involving an earlier liftoff of the funds rate from zero, would be required to forestall this higher inflation, but this would be at the expense of an even weaker labor market.

Figures 7 and 8 show the two alternative scenarios in inflationunemployment space. These figures are similar to figure 6 except that they also include the baseline forecast for comparison. Under faster deleveraging, unemployment falls faster and inflation rises by more than in the baseline. The economy crosses the 7 percent unemployment threshold in 2012Q3 and reaches the 3 percent inflation threshold in late 2013. Therefore, adherence to the $7 / 3$ threshold policy dictates liftoff from the ZLB in late 2012. Given the improvement in the economy and labor markets, an earlier exit seems palatable.

We now consider the higher-expected-inflation scenario. Note that generating the increase in inflation expectations in this scenario requires a shock that is more than 4 standard deviations of the inflation anchor innovation as estimated in the precrisis sample. The resulting forecast, condi-

35. Given the high persistence of the inflation anchor, the increase in average expected inflation over the next 40 quarters is actually hump shaped, and therefore higher in later quarters. 
Figure 7. Inflation and Unemployment in the Forecast with Shorter Deleveraging

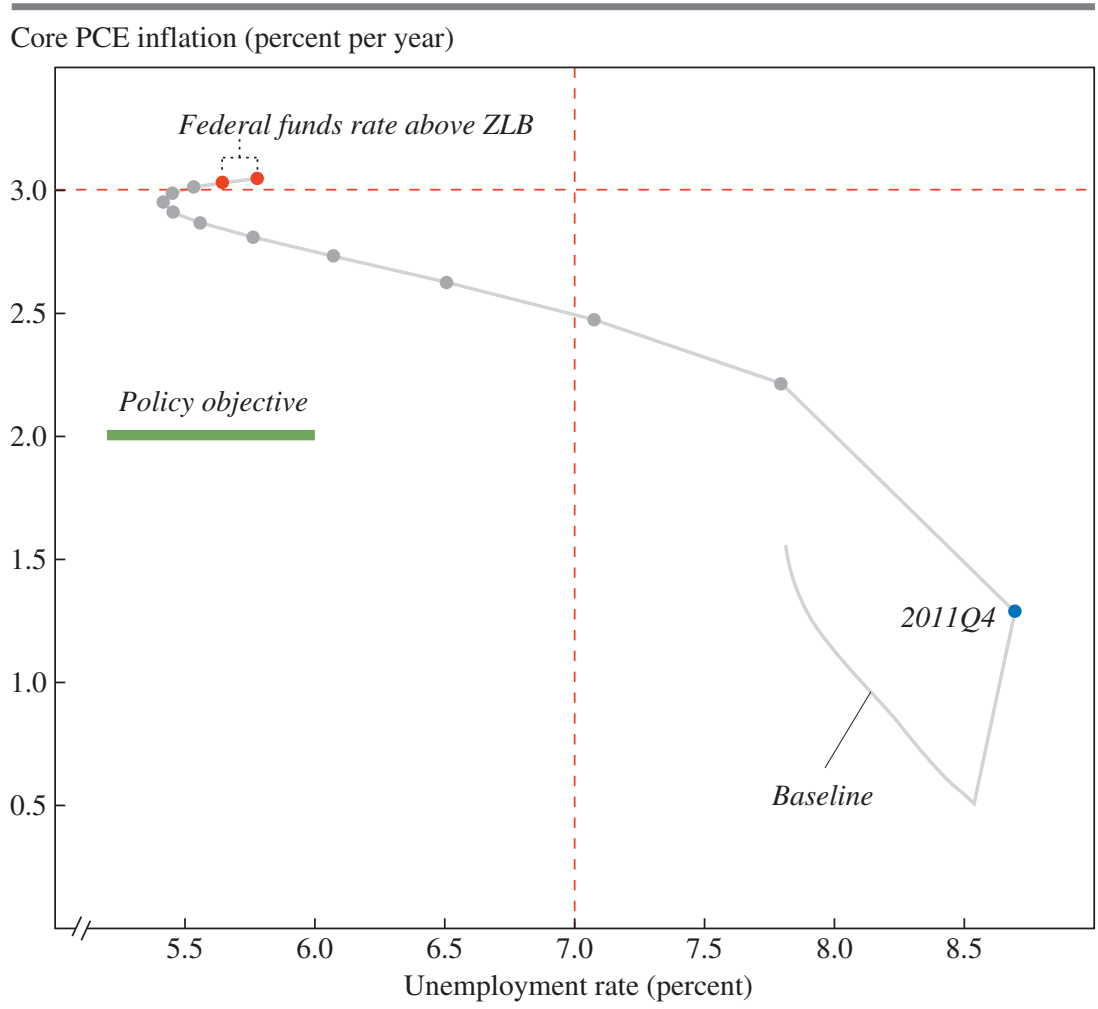

Source: Projections of the authors' model described in the text.

tioning on exceptionally low rates through at least the next 10 quarters, does generate a boom in GDP growth. However, because of the strong real and nominal rigidities we have estimated, neither unemployment nor inflation crosses its threshold within the next 3 years. The unemployment rate skirts its 7 percent threshold without crossing it, and inflation remains well below its 3 percent threshold, through the end of 2014. Although the 7/3 threshold policy would dictate keeping rates at the ZLB in this scenario, the turn in the direction of unemployment toward the end of the forecast horizon is worrisome.

This scenario illustrates a striking feature of New Keynesian models estimated using post-1970s data. Because of the very flat price Phillips curve, very large innovations to inflation expectations do not lead to high inflation even with extraordinarily accommodative monetary policy, at least over a 3-year horizon. This result depends on the assumed credibility 
Figure 8. Inflation and Unemployment in the Forecast with Higher Expected Inflation

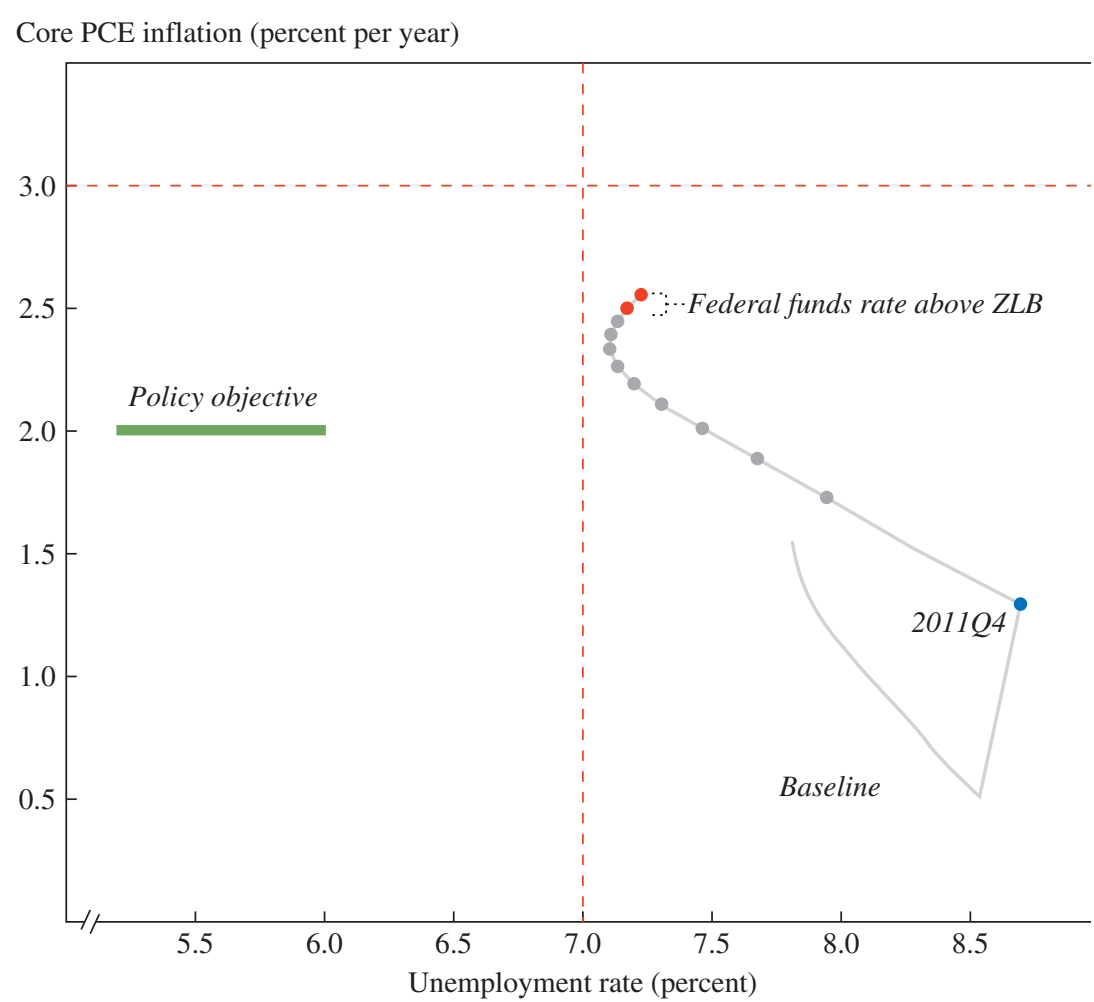

Source: Projections of the authors' model described in the text.

of the model's policy rule and invariance of price setting behavior to inflation expectations. If attempted use of Odyssean forward guidance weakens credibility or changes price setting behavior, this kind of policy experiment might be very misleading. Nevertheless, nothing in the experience of the last 25 years suggests that a persistent change in inflation expectations necessarily generates a destabilizing loss of credibility.

\section{Conclusion}

The empirical context we have provided shows that the FOMC has extensive experience at broadcasting its intended responses to macroeconomic developments. Indeed, macroeconomic forecasters and market participants anticipate about 80 percent of the FOMC's deviations from a simple 
interest rate rule. These communications have not been limited to a single "tight-versus-loose" dimension. The FOMC successfully informed markets that it would accelerate its accommodation in late 2001 and early 2002 and accelerate its removal. Our results also show that surprises associated with FOMC policy announcements substantially influence Treasury bond rates, corporate borrowing rates, and private macroeconomic forecasts. News of substantial monetary tightening raises interest rates as expected, but it also raises inflation forecasts and lowers unemployment forecasts. This counterintuitive finding suggests to us that private forecasters believe that nonpublic information held by the Federal Reserve about future economic conditions instigates some FOMC actions that were unanticipated by the public. That is, the public sometimes imputes Delphic content to policy announcements that are not explicitly tied to economic fundamentals.

As expressed in its April 2012 statement, the most recent as of this writing, the FOMC “. . . anticipates that economic conditions-including low rates of resource utilization and a subdued outlook for inflation over the medium run-are likely to warrant exceptionally low levels for the federal funds rate at least through late 2014." We began this paper by asking whether this statement reflects an Odyssean commitment to lower rates or a Delphic forecast of economic conditions and the FOMC's likely response to them. Our empirical results reassure us that communications difficulties present no insurmountable obstacle to the FOMC stressing the Odyssean interpretation and thereby providing additional monetary accommodation, but other objections to such a policy remain. In particular, one might worry that an Odyssean commitment to low rates places the FOMC's price stability mandate in jeopardy.

We have addressed this concern by using the Chicago Federal Reserve Bank's estimated DSGE model to simulate two adverse scenarios. In the first, the deleveraging process presently keeping the economy at the ZLB accelerates and finishes sooner than expected, and in the second, long-run inflation expectations suddenly rise 1 full percentage point. We compare both simulations with the "bright-line" threshold policy proposal of Evans (2011), which calls for rate increases to begin when either unemployment falls below 7 percent or medium-term expected annual inflation rises above 3 percent. With faster deleveraging beginning in 2012Q1, the unemployment rate falls below its threshold for triggering rate increases in 2012Q3. In this case the policy provides useful insurance against the inflationary consequences of an unforeseen economic recovery. With an exogenous rise in inflation expectations occurring in 2012Q1, the economy comes close to (but does not cross) the unemployment threshold at the start of 2014 
and comes nowhere near the inflation threshold. We conclude from these experiments that the risks of Odyssean forward guidance to the Federal Reserve's price stability mandate can be managed with such conditional forward guidance.

ACKNOWLEDGMENTS We are grateful to Marco Bassetto and Spencer Krane for many stimulating discussions on forward guidance, and to Charles Calomiris, Hesna Genay, David Reifschneider, John Williams, Michael Woodford, and the editors for comments on earlier drafts. We thank Refet Gürkaynak and Eric Swanson for sharing their data with us. Jacob Fabina, Matt Olson, and Christine Ostrowski provided expert research assistance. The views expressed here are those of the authors and do not necessarily represent those of the Federal Reserve Bank of Chicago, the Federal Reserve System, or its Board of Governors. 


\section{References}

Brave, Scott, Jeffrey Campbell, Jonas Fisher, and Alejandro Justiniano. 2012. "The Chicago Fed DSGE Model.” Working Paper no. 2012-02. Federal Reserve Bank of Chicago.

Christiano, Lawrence J., Martin Eichenbaum, and Charles L. Evans. 2005. "Nominal Rigidities and the Dynamic Effects of a Shock to Monetary Policy." Journal of Political Economy 113, no. 1: 1-45.

Christiano, Lawrence, Martin Eichenbaum, and Sergio Rebelo. 2011. "When Is the Government Spending Multiplier Large?” Journal of Political Economy 119, no. 1: 78-121.

Cúrdia, Vasco, Andrea Ferrero, Ging Cee Ng, and Andrea Tambalotti. 2011. "Evaluating Interest Rate Rules in an Estimated DSGE Model.” Working Paper no. 510. Federal Reserve Bank of New York.

Eggertsson, Gauti B., and Michael Woodford. 2003. "The Zero Bound on Interest Rates and Optimal Monetary Policy.” BPEA, no. 1: 139-211.

Eichenbaum, Martin, and Jonas D. M. Fisher. 2007. "Estimating the Frequency of Price Re-optimization in Calvo-Style Models." Journal of Monetary Economics 54, no. 7: 2032-47.

Ellingsen, Tore, and Ulf Söderström. 2001. "Monetary Policy and Market Interest Rates." American Economic Review 91, no. 5: 1594-1607.

Evans, Charles. 2011. "The Fed's Dual Mandate Responsibilities and Challenges Facing U.S. Monetary Policy." Remarks delivered at the European Economics and Financial Centre Distinguished Speaker Seminar, London, September 7.

_. 2012. "Monetary Policy in a Low-Inflation Environment: Developing a State-Contingent Price-Level Target." Journal of Money, Credit and Banking 44 (Issue Supplement s1).

Gagnon, Joseph, Matthew Raskin, Julie Remache, and Brian Sack. 2010. "LargeScale Asset Purchases by the Federal Reserve: Did They Work?" Working paper. Federal Reserve Bank of New York.

Galí, Jordi, and Mark Gertler. 1999. "Inflation Dynamics: A Structural Econometric Analysis." Journal of Monetary Economics 44, no. 2: 195-222.

Gilchrist, Simon, Alberto Ortiz, and Egon Zakrajšek. 2011. "Credit Risk and the Macroeconomy: Evidence from an Estimated DSGE Model." Working paper. Boston University.

Gürkaynak, Refet, Brian Sack, and Eric Swanson. 2005. "Do Actions Speak Louder Than Words? The Response of Asset Prices to Monetary Policy Actions and Statements." International Journal of Central Banking 1, no. 1: 55-93.

Hamilton, James D., Seth Pruitt, and Scott Borger. 2011. "Estimating the MarketPerceived Monetary Policy Rule." American Economic Journal: Macroeconomics 3, no. 3: 1-28.

Justiniano, Alejandro, Giorgio E. Primiceri, and Andrea Tambalotti. 2011. "Investment Shocks and the Relative Price of Investment." Review of Economic Dynamics 14, no. 1: 101-21. 
Krane, Spencer D. 2011. "Professional Forecasters' Views of Permanent and Transitory Shocks to GDP." American Economic Journal: Macroeconomics 3, no. 1: 184-211.

Krishnamurthy, Arvind, and Annette Vissing-Jorgensen. 2011. "The Effects of Quantitative Easing on Interest Rates: Channels and Implications for Policy." BPEA, no. 2: 215-66.

Krugman, Paul R. 1999. “It's Baaack: Japan's Slump and the Return of the Liquidity Trap.” BPEA, no. 2: 137-87.

Kuttner, Kenneth N. 2001. "Monetary Policy Surprises and Interest Rates: Evidence from the Fed Funds Futures Market." Journal of Monetary Economics 47, no. 3: 523-44.

Kydland, Finn E., and Edward C. Prescott. 1977. "Rules Rather Than Discretion: The Inconsistency of Optimal Plans." Journal of Political Economy 85, no. 3: 473-92.

Laséen, Stefan, and Lars E. Svensson. 2011. “Anticipated Alternative Policy-Rate Paths in Policy Simulations.” International Journal of Central Banking 7, no. 3: $1-35$.

Reifschneider, David, and John C. Williams. 2000. "Three Lessons for Monetary Policy in a Low-Inflation Era." Journal of Money, Credit, and Banking 32, no. 4: 936-66.

Romer, Christina, and David Romer. 2000. "Federal Reserve Information and the Behavior of Interest Rates." American Economic Review 90, no. 3: 429-57.

Rudebusch, Glenn D., and John C. Williams. 2008. "Revealing the Secrets of the Temple: The Value of Publishing Central Bank Interest Rate Projections." In Asset Prices and Monetary Policy, edited by J. Y. Campbell. University of Chicago Press.

Sbordone, Argia. 2006. "U.S. Wage and Price Dynamics: A Limited Information Approach.” International Journal of Central Banking 2, no. 3: 155-91.

Smets, Frank, and Rafael Wouters. 2007. "Shocks and Frictions in US Business Cycles: A Bayesian DSGE Approach.” American Economic Review 97, no. 3: 586-606.

Swanson, Eric T., and John C. Williams. 2012. "Measuring the Effect of the Zero Lower Bound on Medium- and Longer-Term Interest Rates." Working Paper no. 2012-02. Federal Reserve Bank of San Francisco.

Taylor, John B. 1993. "Discretion versus Policy Rules in Practice." CarnegieRochester Conference Series on Public Policy 39: 195-214.

_. 1999. "An Historical Analysis of Monetary Policy Rules." In Monetary Policy Rules, edited by J. B. Taylor. University of Chicago Press.

Werning, Iván. 2012. "Managing a Liquidity Trap: Monetary and Fiscal Policy." Working paper. Massachusetts Institute of Technology.

Wright, Jonathan. 2012. "What Does Monetary Policy Do to Long-Term Interest Rates at the ZLB?" Working paper. Johns Hopkins University. 


\section{Comments and Discussion}

\section{COMMENT BY}

CHARLES W. CALOMIRIS This impressive paper by Jeffrey Campbell, Charles Evans, Jonas Fisher, and Alejandro Justiniano contains many useful facts about monetary policy, and its existence itself is an interesting fact, because one of its authors is an important monetary policymaker seeking to influence Federal Reserve actions and the market's perceptions of them. Charles Evans is among the most aggressive advocates of monetary expansion within the central bank, and he has elsewhere proposed a novel approach to expansion, called the "7/3" approach. Under that proposal the Federal Reserve would not only expand the money supply but promise to continue expanding it so long as the unemployment rate is above 7 percent, unless the annual inflation rate rises above 3 percent. To build his case for such a new policy commitment, Evans has written this paper with three other economists at the Federal Reserve Bank of Chicago, arguing, first, that the Federal Reserve has already been making similar sorts of policy commitments, and second, that these commitments have been very effective policy tools.

The central factual claim in the paper is that forward guidance by the Federal Reserve has not merely provided information to the markets, in what the authors term "Delphic" forward guidance; they argue that some of the observed market consequences of forward guidance can only be understood as evidence of a perceived commitment by the Federal Reserve to the markets, which the authors label "Odyssean" forward guidance. In their view this evidence of market reactions to Federal Reserve commitments shows how powerful such commitments can be, and therefore buttresses the case for more of the same today (the $7 / 3$ proposal).

As every student of Homer's classics is aware, however, there is more than one possible meaning for the term "Odyssean policy." In Homer's 
Odyssey, Odysseus did indeed use a commitment device to prevent himself from falling prey to the song of the Sirens (the meaning the authors intend in referring to "Odyssean" forward guidance), but in the Iliad he also was the architect and perpetrator of the most effective deception in the history of warfare. Just as the Trojan Horse helped the Greeks convince the Trojans to abandon their defenses, so might an advocate of new monetary commitments lower the guard of markets and other policymakers by persuading them that the Federal Reserve has made such commitments successfully in the past. Which of these two "Odyssean" policies does this paper do more to illuminate, the power of past Federal Reserve commitments, or the wishful thinking of a policymaker flogging the monetary equivalent of a Trojan Horse?

As a close follower of the Federal Reserve and its policy pronouncements, I reacted with something of a shock to the claim that it has been using forward guidance to make successful commitments to markets in recent years. A commitment is defined as a credible promise to do something. The authors use the same words to define commitment in the first page of their paper. For example, we can agree that Evans's 7/3 policy proposal would be a real commitment, since it would enunciate a clear contingent policy for the future, based on observable phenomena (inflation and unemployment), which would thereby allow the Federal Reserve to be held accountable, through loss of reputation in the markets, for violating that commitment. In macroeconomic theory, the usefulness of a commitment is to overcome the problem of time inconsistency by binding oneself today to a policy action in the future that is long-run optimal from today's perspective but that will not be optimal to choose in the future.

By this definition, nothing the Federal Reserve has done through its forward guidance can reasonably be construed as a commitment. Certainly, the plain language of its forward guidance statements does not constitute promises. For example, in its most recent statements the Federal Reserve "anticipates," but does not promise, that interest rates will remain unchanged through 2014. It explicitly reserves the right to change its policies as economic circumstances change. Furthermore, policymakers at the Federal Reserve often draw attention to the fact that forward guidance is not a commitment. For example, Charles Plosser (president of the Philadelphia Federal Reserve Bank and an opponent of monetary expansion recently) has emphasized that forward guidance today is a forecast, not a promise, and that the Federal Reserve has explicitly reserved the right to change course if the data on which its forecast is based change (Plosser 
2012). During his recent confirmation hearings, Federal Reserve Board nominee Jeremy Stein agreed with that assessment. Forward guidance before the recent crisis was even less specific and contained no language that could reasonably be construed as a promise.

Is it possible that the Federal Reserve is making implicit commitments through forward guidance, even though its own language and many of its policymakers say otherwise? That does not seem possible. A commitment requires clarity about what is being promised; otherwise it is hard to see how there could be any accountability for violating it. Members of the Federal Open Market Committee (FOMC), both individually and as a group, have used forward guidance to express their beliefs based on current evidence but have never made a commitment. If members were to change their forecasts of economic activity in, say, mid-2013 in response to new information, and then decide to start raising interest rates in late 2013 in light of their new beliefs, that would be entirely consistent with their past forward guidance statements, and it would be hard to see why the Federal Reserve as an institution or the FOMC members as individuals would suffer any loss of reputation as a result. Forward guidance simply entails no commitment, as defined either by macroeconomic theory or by common English usage.

The authors understand English as well as I do, so why do they insist that the Federal Reserve has been making important commitments through forward guidance? Their argument that forward guidance has been used as a commitment is purely empirical. The authors claim to have unearthed facts that prove that forward guidance has been functioning as a commitment device. First, they show that a study of the effects of Federal Reserve statements provides convincing evidence that forward guidance moves federal funds futures prices at the time the guidance is provided to the market. Furthermore, they argue, these changes in futures prices are useful for predicting federal funds rates in the future because they predict Federal Reserve actions, not because they contain information about the short-term state of the economy. If the movements in federal funds futures prices at the time of guidance announcements were correlated only with information about the economy that the Federal Reserve possessed but that markets had not yet understood, then the authors would regard that guidance as "Delphic" but not "Odyssean." Those guidance announcements must be regarded as Odyssean, they argue, because they are not only useful for revealing unknown facts about the economy; they predict future policy actions, conditional on the state of the economy. 
Is this argument correct? No. It ignores two very plausible alternative possibilities: first, that forward guidance provides information to the market about the Federal Reserve's objectives, and second, that forward guidance provides information to the market about the Federal Reserve's beliefs about the long-run natural rate of unemployment (an unobservable variable that underlies the future "deviations" from the Taylor rule that the authors identify).

The Federal Reserve's objectives are only vaguely specified or constrained by statute. Its well-known legislative triple mandate (with respect to inflation, employment, and interest rates) does not specify trade-offs among those three objectives. The Federal Reserve recently announced a desire to target inflation at about 2 percent per year over some unspecified long run. It is well known that the Federal Reserve thinks about policy in the context of Taylor rules, at least in part, but also that it employs more than one version of the Taylor rule when thinking about its policy options, and that it has made no explicit commitment to using any particular version of the Taylor rule. Furthermore, the Federal Reserve has frequently noted that its policy actions reflect policy considerations other than those embodied in the Taylor rule. This was especially true during 2002-05, when the Federal Reserve loosened policy dramatically and deviated consciously from the Taylor rule when doing so. FOMC members discussed special considerations, including oil prices, geopolitical circumstances, and other perceived downside risks, which, they argued, required special actions not contemplated by adherence to the Taylor rule. Thus, Federal Reserve policy cannot be said always to follow a Taylor rule, much less a single, known Taylor rule. Policymakers may at times abandon the Taylor rule, and even to the extent that they adhere to it, one thing that is not known, and which is subject to change, is the relative cost the FOMC members attach to deviations from targeted inflation relative to permitting unemployment to rise above its long-run non-accelerating-inflation (or "natural") rate.

This uncertainty about objectives also reflects the fact that the Federal Reserve is a highly politicized entity. It is subject to substantial political risk because the federal government can change its charter at any time. Indeed, changes in the structure and powers of the Federal Reserve and the mandates under which it operates are frequently proposed. In my experience, FOMC members are quite aware of these risks and very responsive to them, although they never acknowledge this publicly. Thus, both because of changes in the ideological makeup of the FOMC and because of political pressures that its members may feel, the cost weights that the members 
attach to short-term increases in unemployment and inflation are neither known nor immutable. Those weights likely change over time as the result of changes in the membership of the FOMC or in the political pressures that influence their actions. For example, it is often noted in the press that the current Federal Reserve is unusually responsive to the political consequences of high unemployment. One obvious interpretation of market reactions to forward guidance- and one that the authors do not consideris that such guidance reveals something about these changing objectives of the FOMC.

The second obvious alternative explanation for the authors' finding is that forward guidance reveals something about the FOMC's beliefs about the natural rate of unemployment. Even if policymakers employed a rigid Taylor rule, and even if their policy preferences with respect to the costs of deviations of inflation and unemployment from their long-term levels were known, forward guidance could still reveal something to the market about FOMC members' beliefs about the natural rate of unemployment (which is contained within the Taylor rule as an assumption). The natural rate is not a constant, and indeed it can be subject to dramatic and unobservable medium-term change. The authors' model assumes that the natural rate is known to everyone, and for purposes of their analysis they set it equal to a consensus view based on published forecasts. But in practice no one knows what the natural rate is, and everyone wants to know what the members of the FOMC think that it is.

Uncertainty about the natural rate is especially high in the wake of a severe recession. Studies of labor markets show that the ability of unemployed workers to find employment declines with the amount of time they are out of work. During a recession as deep as the recent one, many people are without work for longer periods than under normal economic circumstances (Davis and von Wachter 2011): today a substantial proportion of the unemployed have been unemployed for 2 years or more. Long-term unemployment can reflect secular declines in some industries, and thus the need for sectoral reallocation of workers and retraining before workers are likely to find new jobs. Furthermore, unemployment itself reduces the skill set of workers within their industry, making it hard for the long-term unemployed to find employment even if their sector has not suffered long-term decline. When the economy has just weathered a severe, long-lived recession, one cannot say with any reasonable certainty what the natural rate of unemployment is. It may be 5 percent or it may be 7 percent. Because the natural rate is not a matter of knowledge, much less a matter of common knowledge, uncertainty can arise among market 
participants over what FOMC members believe it to be. Forward guidance, therefore, provides information to the market about the Federal Reserve's beliefs about the natural rate, and the markets' reactions to forward guidance, as measured by the authors, could be interpreted as reflecting, at least in part, changes in those market inferences about the Federal Reserve's beliefs about the natural rate.

For these reasons it is not correct to argue that the evidence presented in the paper regarding federal funds futures markets shows that forward guidance has been Odyssean rather than Delphic. Given the strong prima facie arguments against viewing forward guidance as a form of commitment, it is far more likely that FOMC statements have affected market perceptions of the Federal Reserve's changing objectives and beliefs.

All of this does not mean that the authors are wrong to advocate for a "bright-line" rule like Evans's proposed 7/3 commitment. It simply means that any argument for such a rule must be guided mainly by theory rather than experience. There is certainly a respectable case to be made (building, for example, on the logic of Eggertsson and Woodford 2003) that some version of a 7/3 rule could credibly place the Federal Reserve's reputational capital at risk, and thereby constitute a credible commitment to maintain expansion into the future, which could add to the stimulative effect of monetary loosening. I also agree with the authors that such a two-sided commitment could potentially mitigate inflation risk by binding the Federal Reserve to react to accelerating inflation in the future through an explicit commitment not to tolerate rising inflation.

Still, I do not support further action by the Federal Reserve to loosen at this time, even if accompanied by a bright-line $7 / 3$ rule. I see little potential short-term gain to the economy from further reducing long-term interest rates (which are already at historic lows) by a few basis points. A few more basis points reduction in long-term bond rates will not do much to address the deep problems (including fiscal policy uncertainties) that are constraining current economic growth. Nor do I believe that the authors' modified DSGE model's estimates, based on past observations, are very relevant for gauging the extent of inflation risk going forward. The risks faced by the Federal Reserve in the future reflect particular circumstances related to its balance sheet structure and to the political constraints under which it operates. These factors imply extraordinary circumstances and unique new sources of inflation risk. When these are taken into account, the risk-reward ratio for further expansionary monetary policy is very poor. The time has come for the Federal Reserve to end its quantitative easing policies, and to begin to phase in a gradual, preannounced increase 
in reserve requirements. Such an increase, if designed properly, would have no discernible immediate effect on economic activity but would be a crucial safeguard against future inflation, and it would produce an orderly transition to the inevitable tightening of monetary policy sometime in the future. Excess reserves are very large at the moment. An increase in required reserves would have virtually no effect on the current supply of money or the current supply of lending (for a historical parallel see Calomiris, Mason, and Wheelock 2011). The most likely immediate response by banks, if any, would be to reduce their Treasury holdings, shifting them into cash.

In my view there are two independent reasons to move to higher long-run reserve requirements. First, much higher (and remunerated) reserve requirements are desirable as a long-term prudential tool to complement capital requirements (Calomiris, Heider, and Hoerova 2011, Calomiris 2012). Cash reserve requirements are observable and hence credible protections for insured deposits, unlike capital requirements, which are accounting artifacts prone to manipulation by bankers and supervisors. Furthermore, cash holdings have important incentive consequences for effective bank risk management, because higher cash-to-asset ratios limit the losses borne by deposits for any given loss in risky assets. Book capital ratio requirements in the banking system are a recent prudential tool (in the United States, they began to be used only in 1981) and lack a track record of much success. Cash ratio requirements have a much longer and more effective history. It is high time to restore substantial cash ratio requirements as part of the prudential regulatory toolkit.

Second, the high level of excess reserves in the banking system, combined with the structure of the Federal Reserve's asset portfolio, presents a substantial risk of future inflation if banks at some point choose to convert those excess reserves into loans. Some monetary policymakers see the Federal Reserve's commitment to low inflation as already sufficiently credible, and others (including Evans and other proponents of the $7 / 3$ proposal) argue that a bright-line rule would add to that credibility by announcing not only a long-run objective but also a short-run constraint on the tolerance for inflation. In my view, however, Federal Reserve policymakers are too sanguine about their ability to contract the money supply in the future in reaction to a sharp rise in loan supply by banks, especially if that increase were to occur alongside an increase in long-term interest rates.

The experience of the 1930s shows that loan supply can jump very quickly following a severe banking crisis. From 1933 to 1939, total lending 
by Federal Reserve member banks was essentially flat. From December 1939 to December 1941, loans rose by roughly 20 percent. It is not farfetched to argue that a similar surge in bank lending could occur today.

Federal Reserve officials argue that they have all the tools they need to contract the money supply as necessary, even though they have tripled the amount of high-powered money relative to its precrisis level. They point to the potential use of contractionary open-market operations, increases in the interest rate paid on excess reserves, and the use of reverse repurchase agreements as tools that they could employ in addition to reserve requirement increases. I do not find those arguments very convincing. The central problem that policymakers do not like to recognize is the political risk the Federal Reserve could face from employing some of these policy tools.

Consider the problem of relying on contractionary open-market operations if bond market yields and bank loan supply both rose suddenly. The key problem is that significant sales of the long-term Treasuries or mortgage-backed securities necessarily used in such operations could, in an environment of substantially higher interest rates, make the Federal Reserve insolvent on an accounting basis (Shadow Financial Regulatory Committee 2010). ${ }^{1}$ Of course, such insolvency would not physically prevent the Federal Reserve from contracting its balance sheet, but the prospect would be a public relations nightmare. It could damage the Federal Reserve's image and lead to an adverse political backlash in Congress, with uncertain consequences. For that reason many observers worry that the Federal Reserve is unlikely to take on the political risks that would attend making itself insolvent on an accounting basis. It might instead choose to delay open-market sales of its assets in response to a sudden increase in interest rates and loan supply. In that case it would have to either accept the inflationary consequences of doing so or rely on other tools to lean against the expansion in the supply of money and loans.

What other tools? Reverse repurchase agreements have been discussed, but it is far from certain that money market mutual funds would be willing to engage in these transactions on the necessary scale, and some market participants have expressed skepticism that this would be feasible. Higher interest on excess reserves could help to limit bank expansion of loans and deposits, but the elasticity of demand for excess reserves is unknown, and

1. See also Charles W. Calomiris, "An Insurance Policy Against Inflation," The Wall Street Journal, March 12, 2012; Charles W. Calomiris and Ellis Tallman, "In Monetary Targeting, Two Tails Are Better Than One," Bloomberg Businessweek, November 18, 2010. 
during a spike in bank loan supply the rise in interest payments to banks needed to entice them to avoid a surge in lending might require a very large expenditure by the Federal Reserve. Such an increase in interest cost, alongside the low interest earned on its assets, could itself produce huge losses at the Federal Reserve that would threaten its accounting solvency.

In other words, in the real world where political forces do shape monetary policy, the Federal Reserve's current balance sheet structure (large amounts of excess reserves combined with assets that will decline in value if long-term interest rates rise) may be an unfortunate form of "commitment device," where the commitment is to restricting open-market operations and potentially to producing undesirable inflation. Given that reality, the prudent thing for the Federal Reserve to do is to recognize that increased reserve requirements are its best tool for preventing increased inflation. A phasing in of increases in reserve requirements though a preannounced plan would be desirable because it would avoid disruptive surprises to the market. Given the implementation delays that will necessarily attend any such shift in reserve requirements, it is high time for the Federal Reserve to begin that process. Waiting to begin until inflation is upon us could result in a significant surge in inflation.

\section{REFERENCES FOR THE CALOMIRIS COMMENT}

Calomiris, Charles W. 2012. "Getting the Right Mix of Capital and Cash Requirements in Prudential Bank Regulation." Journal of Applied Corporate Finance 24: $33-41$.

Calomiris, Charles W., Florian Heider, and Marie Hoerova. 2011. "A Theory of Bank Liquidity Requirements." Working paper. Columbia Business School (November).

Calomiris, Charles W., Joseph R. Mason, and David C. Wheelock. 2011. "Did Doubling Reserve Requirements Cause the Recession of 1937-1938? A Microeconomic Approach.” Working Paper no. 16688. Cambridge, Mass.: National Bureau of Economic Research (January).

Davis, Steven J., and Till von Wachter. 2011. "Recessions and the Costs of Job Losses." BPEA, no. 1: 1-55.

Eggertsson, Gauti B., and Michael Woodford. 2003. "The Zero Bound on Interest Rates and Optimal Monetary Policy." BPEA, no. 1: 139-211.

Plosser, Charles I. 2012. "Economic Outlook and Communicating Monetary Policy." Speech at the Economic Forecast Breakfast and Annual Meeting of the Main Line Chamber of Commerce and the Main Line Chamber Foundation, Gladwyne, Pa., February 1.

Shadow Financial Regulatory Committee. 2010. "Stress Testing the Fed." Statement no. 302. University of Pennsylvania (December 13). fic.wharton.upenn. edu/fic/Policy\%20page/Statement\%20No.\%20302.pdf. 


\section{COMMENT BY}

MICHAEL WOODFORD ${ }^{1}$ This paper by Jeffrey Campbell, Charles Evans, Jonas Fisher, and Alejandro Justiniano addresses a very topical issue, namely, the role of forward guidance in the effective conduct of monetary policy, with particular reference to approaches recently used or contemplated by the Federal Reserve. Whether and how a central bank should communicate its likely future policy stance is always an issue, and some central banks, such as Sweden's Riksbank, routinely publish projected forward paths for their policy rate as part of their communication strategy. But it becomes an especially crucial issue when, as in the United States since December 2008, the policy rate target is at its effective lower bound, so that adjustments of the current policy rate target are no longer given much consideration at meetings of the Federal Open Market Committee (FOMC). It is hardly surprising that explicit statements about likely future policy have become a much more prominent aspect of Federal Reserve communications since that time, and debates about the desirability of such forward guidance have been one of the more contentious issues within the FOMC.

The paper addresses questions of two types. First, how confident can one be that attempts at forward guidance matter at all? Do such statements by a central bank actually change the expectations of market participants, and hence economic outcomes, or do only the bank's actual trades matter, and not what it may say about them? And second, to the extent that one believes that this dimension of policy matters, how should it best be used? Is the kind of forward guidance used thus far by the FOMC the right kind?

The authors seek to assess the effectiveness of forward guidance in influencing expectations using two distinct methodologies. The first of these updates and extends the important previous work of Refet Gürkaynak, Brian Sack, and Eric Swanson (2005). This approach looks at whether market expectations of the forward path of short-term interest rates seem to change over a narrow time window (from half an hour to a full day) around the release of an FOMC statement; the idea is that if the window is narrow enough, one can be fairly confident that the only important "news" that should have changed expectations over this interval was the news in the FOMC statement. The method cannot, by its nature, reveal anything about why market participants forecast a different forward path for interest rates after release of the statement than before, or which aspect of the statement constitutes the news that changes their beliefs; but it can test the null

1. Thanks are due to Kyle Jurado for research assistance and to the National Science Foundation for supporting my research on this issue under grant number SES-0820438. 
hypotheses that FOMC announcements do not change the expectations of market participants at all (that speech is irrelevant) or that the only news in a postmeeting statement is the revelation of the new (current) operating target for the federal funds rate.

Gürkaynak and his coauthors use the change in the federal funds futures price after an FOMC announcement to infer the change in market expectations for the funds rate at various horizons. They use principal components analysis to extract the two most important "factors" explaining movements in the forecasted funds rate at the various horizons, and they orthogonalize these two factors so that the loading on one factor (the "target" factor) is equal to the change in the forecast of the current federal funds target (the one that will apply immediately after the meeting), while the other factor (the "path" factor) involves no change in the forecast of the current target, only changes in forecasts of the funds rate at more distant horizons. Under the null hypothesis of no effect of the statements on expectations, there should be no appreciable variation in either factor. Under the null hypothesis that the only news is the revelation of the current target, all variations in the forecasted path of the funds rate should be accounted for by the target factor alone. Instead, Gürkaynak and coauthors find that the path factor accounts for an important degree of variation in funds rate forecasts.

The present authors extend their work to a longer data sample and find similar results. For their sample of statements between February 1994 and June 2007 (that is, from the time that the FOMC began issuing a statement about the policy decision after each meeting until the onset of the subprime crisis), they find that the path factor accounts for 67 percent of the variation in the expected funds rate 2 quarters in the future, and 90 percent 4 quarters in the future. For their sample of statements between August 2007 and December 2011 (treated separately because of the numerous novel aspects of communication policy during and since the crisis), the path factor is associated with changes in the expected funds rate further in the future but continues to be important: it accounts for 53 percent of variation in forecasts 4 quarters in the future, and 79 percent 6 quarters out.

These findings indicate that FOMC announcements were able to shift expectations about the future path of the funds rate, and not simply through the announcement of a new current target. Some other aspect of the announcement must have been conveying information about future policy, over and above whatever inference about future policy could be made on the basis of the new funds rate target itself. These changes in expectations about future policy, furthermore, affected behavior, at least in asset markets, for Gürkaynak and coauthors (2005) also find that their path factor 
is correlated with changes in Treasury yields over the same time window. The present authors confirm this and also find highly significant effects on corporate bond yields.

As already noted, an important limitation of this approach is that it provides no information about what aspect of FOMC statements influences expectations. Do market participants accept at face value what the FOMC declares about future policy, or do they form their own inferences about likely FOMC policy from other clues in the statements? More important, do their forecasts of the future funds rate change because the statement changes their beliefs about the FOMC's reaction function, or because it changes their forecasts of economic conditions that are expected to determine FOMC policy change, as a result of inferences they make from the statement about information available to the FOMC? The latter question - to use the authors' terminology, whether the guidance provided by the statements is Odyssean or Delphic - is important for determining whether statements can change expectations about the way that a central bank will conduct policy in the future, which is the goal of forward guidance.

In at least some cases, the forecast changes do coincide with attempts by the FOMC to provide explicit forward guidance about policy. For example, the largest value of Gürkaynak and coauthors' (2005) path factor occurred on January 28, 2004, following an FOMC meeting at which the funds rate target (which had been held constant at a floor of 1 percent since the previous June) was not changed, but the reference to maintaining policy accommodation "for a considerable period," included in each postmeeting statement since the previous August, was replaced by a declaration that "the Committee believes it can be patient in removing policy accommodation." It seems likely that the substantial change in funds rate expectations, despite no change in the current target and no surprise in that regard, was mainly due to this change in language, which was evidently taken to indicate that the FOMC would begin raising the funds rate target sooner than had previously been expected. But even in such a case, one cannot easily say whether this response reflected successful signaling of a change in the FOMC's reaction function, or simply an inference that the change in language indicated that the FOMC's information predicted a stronger economy.

Reasons for doubt are provided by the results presented in this paper on the extent to which the news in FOMC statements predicts changes from month to month in Blue Chip Economic Indicators forecasts of unemployment and consumer price inflation. The authors find that positive values of both the target factor and the path factor are associated with downward 
revisions of unemployment forecasts, and upward revisions of inflation forecasts, in the next month's Blue Chip survey after the FOMC statement in question. Both signs are opposite to what one would expect if the news that led to a higher expected path of the federal funds rate was a shift in the FOMC reaction function toward tighter policy under given economic conditions, but they are exactly what one would expect if there were no change in beliefs about the reaction function, but instead there was news that the economy was likely to be stronger than previously expected. Of course, there could be some news of both kinds, but one cannot say that these results provide clear evidence of an ability to change beliefs about the reaction function.

The authors propose to remedy some of the obvious limitations of Gürkaynak and coauthors' (2005) event-study methodology by also using a second approach. This approach uses survey forecasts of future interest rates, inflation, and unemployment at various horizons to measure forecastable deviations from a Taylor-type reaction function. (As before, the market forecasts of the future federal funds rate path are inferred from federal funds futures prices, and forecasts of inflation and unemployment are taken from the Blue Chip survey.) The existence of forecastable deviations from a simple Taylor rule (that is, funds rate forecasts different from those that should be implied by the inflation and unemployment forecasts, if one expected the funds rate to be set in the future using a linear function of inflation and unemployment) is interpreted as indicating the existence of effective forward guidance. The authors call the innovations in these forecastable departures "forward guidance shocks"; once such shocks can be measured, one can then consider their effects on other variables to determine whether forward guidance successfully influences anything besides the expected path of the federal funds rate.

The authors find that substantial forecastable deviations from the Taylor rule exist: more than 80 percent of the variation in the residual of the Taylor rule is attributed to forward guidance shocks 1 to 4 quarters earlier, and about 40 percent to shocks as early as 3 to 4 quarters earlier. The authors argue on this ground that "the public and the FOMC together have extensive experience with the communication of relatively short term forward guidance." They also find, as with the path factor identified using Gürkaynak and coauthors' methodology, that their forward guidance shocks are associated with changes in yields on Treasuries and corporate bonds. They conclude that "it seems possible for the FOMC to influence longer-term interest rates that are outside of its direct control by communicating its intention to lower the short-term policy rate persistently." 
The authors appear to believe that identifying movements in forecasts of Taylor rule residuals, rather than simply forecasts of the future federal funds rate, solves the problem of distinguishing forward guidance from mere news about the economic outlook. But this is only true to the extent that one can be confident that people's beliefs about the FOMC reaction function, in the absence of forward guidance, are correctly specified by the particular Taylor rule that the authors use. If they are not, then even in the absence of any change in beliefs about the reaction function, news about the economic outlook could result in changed forecasts for the residual of the (incorrectly specified) Taylor rule.

In fact, the results in table 9 of the paper suggest an interpretation of the latter kind. The authors find that positive forward guidance shocks identified using their method (supposedly, signals that the FOMC will deviate from its normal reaction function a quarter or two later, in the direction of tighter policy than usual) are correlated with downward revisions in unemployment forecasts for the next few quarters. This is the opposite of the conclusion that ought to be drawn from news that the current FOMC is more "hawkish" than past committees have typically been. The authors themselves provide a potential interpretation of the finding, in terms of what they call a "history-dependent" reaction function. Under this more complex policy (their equation 4), a decrease in unemployment results in a larger increase in the funds rate target if the decrease was not forecastable a couple of quarters earlier than if it was forecastable.

The authors draw a distinction between this kind of interpretation of the results in table 9 and what they call "simple reverse causality" from unemployment to the policy rate. But it is in fact an explanation in terms of reverse causality-albeit one that involves a more complex dynamic relationship between unemployment and the target rate than the one specified in their baseline reaction function. More to the point, it is an explanation that undermines their desired interpretation of the $v_{t, j}$ shocks as "forward guidance shocks." If equation 4 correctly describes FOMC policy, the identified residual $v_{t, 1}$ will reflect changes in the forecast of $\widetilde{u}_{t+1}$ over the course of quarter $t$, even in the absence of any true stochastic shifts in the reaction function. Since it is surely the case thaf $\widetilde{u}_{t+1}$ (which is actually an average of the unemployment rate over quarters $t$ through $t+2$, as estimated at the beginning of quarter $t+2$ ) will not be completely forecastable by the beginning of quarter $t$, the variation in this residual would surely be an overestimate of the actual degree of forecastable departure from the typical reaction function (that is, from equation 4 with no stochastic terms). And significant variation 
in this residual need not imply the existence of true forward guidance shocks at all.

Moreover, even if one supposes that the forward guidance shocks that the authors identify really do represent changes in expectations about future deviations from the FOMC's usual reaction function, evidence that such changes in policy expectations occur would not in itself prove that the FOMC has been able to control those expectations through its announcements. This second method of the authors, given that it is based on monthly data rather than data from a window of hours or days, can at best identify only the changes in policy expectations that occur during a given month, regardless of the reasons for the changes in beliefs; there is no reason to tie them to FOMC announcements, and certainly no reason to tie them to the FOMC's deliberate attempts to influence beliefs about its policy, as opposed to developments that "reveal the type" of the current FOMC, possibly inadvertently.

One must therefore conclude that the authors provide little direct evidence that the FOMC is able to change expectations about its future policy when it wishes to. In particular, although I believe that FOMC statements have been able to change market forecasts of the path of the funds rate, it is not clear that they have done so by changing beliefs about the FOMC's reaction function, as opposed to changing beliefs about the economic outlook. I do not think, however, that there is evidence that the FOMC would not be able to change beliefs about its systematic approach to policy were it to speak about this. Instead, there have been few if any occasions on which such Odyssean forward guidance has been attempted.

As the paper documents, the FOMC has for some time offered various types of hints about the likelihood of future adjustments of its federal funds rate target. Since the funds rate reached the zero lower bound in December 2008, these statements have been much more explicit (and refer to policy rates much further in the future) than had previously been the case. Nonetheless, the FOMC's communication about future policy—both through its postmeeting press releases and through the information about individual participants' forecasts of the funds rate path provided in the quarterly Survey of Economic Projections-has taken only the form of predictions about the future path of the funds rate, given what can be known at present. No indication of a decision to change the FOMC's policy rule is ever given; it is thus always possible to interpret the FOMC's announcements about future policy as simply reflecting changes in the FOMC's view of likely future economic conditions, and hence the path of the funds rate 
that can be expected under the committee's normal reaction function. For example, when the FOMC announced on January 25, 2012, that "the Committee ... currently anticipates that economic conditions ... are likely to warrant exceptionally low levels for the federal funds rate at least through late 2014"- arguably the Committee's most aggressive use of forward guidance in its history - the headline of the New York Times online story about the announcement was "Fed Signals That a Full Recovery Is Years Away." 2 Although the shift in the OIS (overnight index swap) yield curve indicates that market forecasts of the funds rate several years in the future fell after the announcement, this might have been a response to expectations of a slower recovery rather than to any understanding that FOMC policy had changed.

Is this not the only prudent form of forward guidance for a central bank to offer? If one supposes that the only alternative would have been for the FOMC to offer an explicit promise to keep the funds rate target at zero to 25 basis points until late in 2014 , then one might think so; a nonstate-contingent commitment extending almost 3 years into the future would surely have been unwise. The resort to a mere prediction might seem a clever way of allowing for state contingency without having to explain all the possible contingencies; the FOMC would be saying what the path of the funds rate will be if things develop in the way that can be anticipated given what it knows now, while making it clear that this is only the committee's current anticipation-policy may have to be different if unexpected developments arise.

It is certainly right that a desirable form of forward guidance-if it involves communication about anything but a fairly short horizon-would not make unconditional promises about the future path of the funds rate. Since the authors refer to the "late 2014" statement language as implementing "the policy recommendations of Eggertsson and Woodford (2003)," I should point out that Eggertsson and Woodford (2003) do not argue for the desirability of a commitment to keep the policy rate at zero for a fixed period. Rather, we argue for the desirability of a commitment to conduct

2. The New York Times, January 25, 2012 (www.nytimes.com/2012/01/26/business/ economy/ fed-to-maintain-rates-near-zero-through-late-2014.html?pagewanted=all). The Federal Reserve itself took some pains to deny that it was attempting to provide Odyssean forward guidance through its statement. Chairman Ben Bernanke was quoted in the Times article as saying during the press conference following the release of the statement, "I wouldn't overstate the Fed's ability to massively change expectations through its statements," although, he offered, "it's important for us to say what we think." 
policy in a different way than a discretionary central banker would wish to ex post, and we show that (in our New Keynesian model) the optimal commitment involves keeping the policy rate at zero for some time after the point at which a forward-looking inflation-targeting central bank (or a central bank following a forward-looking Taylor rule) would begin to raise interest rates. But the date $T$ until which the policy rate should be kept at zero is not a date that can be announced with certainty at the time of the shock that causes the zero lower bound to bind; its optimal value depends on how the economy develops. (In the same paper we illustrate numerically how $T$ should depend on the length of time that the natural rate of interest remains abnormally low, and we give a more general analytical characterization of the optimal policy commitment that implies that $T$ should depend on the evolution of "cost-push" disturbances as well.)

But does this mean that, as a practical matter, mere communication of the forward path that the central bank currently forecasts_-given the currently anticipated path of the economy and the policy rule that the bank intends to follow-is all that is likely to be useful? Unfortunately, such an approach has a serious flaw, which is precisely that a given statement about the change in the anticipated forward path of the policy rate may be subject to multiple interpretations. If an announcement that the date $T$ at which the policy rate will first rise above its lower bound has moved further into the future is interpreted as meaning that the first date at which a standard (purely forward-looking) Taylor rule would require a policy rate above the floor has moved further into the future, because of a weakening of the economic outlook-without in any way challenging the expectation that the bank will, as always, follow such a rule - then the announcement (if also believed) should have a contractionary, not an expansionary, effect on aggregate demand. For rather than implying that, at a certain point in the future, interest rates will be held lower than one would have expected before the announcement (so that real incomes at that later time will be greater than would previously have been expected, and likely inflation as well), the announcement would instead imply that real incomes at that time will be lower than would previously have been expected (and likely inflation as well). Such a change in expectations should reduce current willingness to spend rather than increase it. Forward guidance of this kind would thus have a perverse effect, worse than not commenting on the outlook for future interest rates at all.

The only obvious way to avoid this pitfall is to accompany any discussion of the forward path of interest rates with an explanation of the considerations behind it - in particular, of the policy commitments that the 
anticipated forward path reflects. Discussion of the forward path of interest rates implied by a central bank's policy commitments may well be useful; in many New Keynesian models, anticipations of this forward path are a key element in the transmission mechanism, and a central bank may reasonably not wish to leave it to chance whether market participants will correctly understand the interest rate implications of policy commitments formulated in other terms (say, in terms of acceptable paths for the price level and the unemployment rate). But this does not mean that presentation of the implied forward path for interest rates suffices as an explanation of the bank's policy commitments.

In the case of a central bank at the lower bound for its policy rate, it is important to discuss what will determine the date $T$ at which "liftoff" from the floor should occur, and not simply announce the bank's current estimate (or range of estimates) of that date. The authors suggest one simple form that such an explanation might take, in their reference to the "7/3 threshold rule" proposed by Evans. Adoption of such a commitment by the FOMC would, in my view, be an important improvement upon current communication policy. It would emphasize the conditions for exit from the current extremely accommodative policy stance, rather than an exit date. And the stated conditions would involve both parts of the Federal Reserve's dual legislative mandate, which I believe is also desirable. (The optimal target criterion derived in Eggertsson and Woodford 2003 involves the evolution of both an index of the general level of prices and a measure of the output gap.)

Nonetheless, the Evans proposal fails to incorporate an important feature of the optimal policy commitment in the model of Eggertsson and Woodford (2003), which also characterizes optimal commitments in more general (and more realistic) New Keynesian models for reasons discussed in Woodford (2011). That feature is the commitment to compensate subsequently for misses of the target due to the binding zero lower bound on interest rate policy. The 7/3 threshold rule is an example of a purely forwardlooking criterion for policy: the appropriate policy at any time depends only on the paths for inflation and unemployment that can be achieved from that time onward, independent of the path by which the economy may have reached its current state. In the context of the simple macroeconomic model considered by Eggertsson and Woodford (where inflation and output determination are also purely forward looking), such a rule will not imply any reason to delay immediately returning to the low-inflation steady state as soon as this is consistent with the zero lower bound on interest rates (that is, as soon as the natural rate of interest returns to positive territory); 
it would not imply any commitment to keep the policy rate low for longer than would a strict inflation target or a purely contemporaneous Taylor rule. This means that a credible commitment to such a rule would do nothing to mitigate the problems created by the zero lower bound-which, in a case like the numerical example presented by Eggertsson and Woodford (2003), are quite severe.

A more desirable form of policy commitment would instead involve a commitment to more-inflationary policy for a time, to offset any period of insufficient nominal growth while the zero lower bound constrains policy. If such a commitment is made credible, the expectation that it will be adhered to reduces automatically the risks of deflation or even of significant disinflation while the lower bound binds, because any undershooting of nominal growth should automatically create expectations of more-rapid future nominal growth that provide a motive for smaller price reductions and more modest reductions in expenditure immediately. Eggertsson and Woodford (2003) show numerically that commitment to a fixed target path for an "[output] gap-adjusted price level" (the log of the price index plus a positive multiple of a measure of the output gap) provides a fairly good approximation to the optimal policy commitment in their model. A simpler version of such a proposal - and one that would maintain some of the important advantages of the Eggertsson-Woodford proposal, while being easier to explain to the public-would be a target path for nominal GDP, as proposed by Christina Romer, among others. ${ }^{3}$ It would have been interesting to see simulations of the effects of practical policy proposals of this kind compared with those of a commitment to the 7/3 threshold rule, using the authors' DSGE model.

\section{REFERENCES FOR THE WOODFORD COMMENT}

Eggertsson, Gauti B., and Michael Woodford. 2003. "The Zero Bound on Interest Rates and Optimal Monetary Policy.” BPEA, no. 1: 139-211.

Gürkaynak, Refet S., Brian Sack, and Eric T. Swanson. 2005. "Do Actions Speak Louder Than Words? The Response of Asset Prices to Monetary Policy Actions and Statements." International Journal of Central Banking 1: 55-93.

Woodford, Michael. 2011. "Optimal Monetary Stabilization Policy.” In Handbook of Monetary Economics, vol. 3B, edited by B. M. Friedman and M. Woodford. Amsterdam: Elsevier.

3. Christina D. Romer, "Dear Ben: It's Time for Your Volcker Moment," The New York Times, October 29, 2011. 
GENERAL DISCUSSION David Romer saw the paper's distinction between types of central bank statements-between those that provide information about the central bank's outlook, and those that indicate a departure from the central bank's usual response to a change in the outlookas one of first-order importance. However, he also thought the discussants had made an important clarification, namely, that one reason a central bank might depart from its usual response is that it has other objectives in addition to the standard ones of price stability and maximum employment. During the 1980s, for example, under the Paris and Louvre Accords, the Federal Reserve was concerned with exchange rate objectives. This, Romer argued, was different from departing from usual behavior because one has made an Odyssean commitment.

On the question of whether the Federal Reserve's recent forward guidance was Odyssean, Romer pointed out that the plain language of the Fed's statements did not support such an interpretation. Those statements said explicitly that forecast economic conditions were what warranted low interest rates well into the future; the policy would change if conditions changed. Whether those statements also contained a dog-whistle component, signaling to those in the know that an Odyssean statement was being made, was a harder question to answer.

Finally, Romer offered the prediction that the paper's identification of central bank commitments to departures from its interest rate rule would not turn out to be the definitive one. As evidence he cited the fact that throughout the 1990s and 2000s, when the Federal Reserve seemed to be concerned largely with output and inflation, the authors found, implausibly, that in every quarter the Fed was communicating deviations from its rule.

Responding to Calomiris's formal comment, Robert Hall argued that Finn Kydland and Edward Prescott had demonstrated long ago that a central bank that cannot commit to future actions is doomed to make on-thespot decisions that lead to higher inflation. Ever since then, central banks around the world have taken pains to avoid that trap, and in doing so have shown that central banks can indeed commit. Therefore it was wrong to suggest, as Calomiris had, that such commitments are merely cheap talk, and it was unnecessary to propose that central banks make their commitments credible by expanding their balance sheets. In any event, Hall continued, in the case of the Federal Reserve, such an expansion would not make a commitment to easier policy more credible, because the Fed can engage in monetary contraction any time it wants by paying higher interest on reserves. Indeed, Chairman Bernanke has made it clear that he is prepared to do just that. 
Hall also commented on what he saw as a surprising resurgence of interest in nominal GDP targeting, perhaps due primarily to Christina Romer's work. He recalled that soon after Kydland and Prescott's paper was published, he and Gregory Mankiw had written a paper on that topic. They had undertaken the project thinking that they could show that commitment to such a target might be the best way for a central bank to communicate its objectives. But they soon found that there were so many medium-run sources of disturbance to real GDP that nominal GDP targeting seemed impractical.

Benjamin Friedman saw the paper as an attempt to resolve a conundrum that James Tobin had often struggled with: although economists know that the monetary policy rule that optimizes a central bank's chosen objectives will be highly state-contingent, and thus complex, the effectiveness of any such rule requires that it be simple enough to be understood by the public. This gives rise to a trade-off between flexibility and simplicity that is very difficult to optimize.

Friedman accepted the distinction between Delphic forecasts and Odyssean commitments but thought the authors erred in strictly linking the former to what they called the systematic component of the interest rate setting procedure, and the latter to the deviation component. In fact, Friedman argued, the central bank could state a forecast of either the systematic or the deviation component, and similarly, it could state a commitment, which could be conditional or unconditional, either with respect to the deviation component or to the sum of the two components-it would be illogical, of course, to "commit" with respect to the systematic component. Friedman thought that relaxing that one-to-one identification could help the authors address the difficulties that both discussants had found with the paper's analysis.

Alan Blinder applauded Charles Evans for his willingness to reveal his thoughts on monetary policy to the Brookings Panel while still a member of the Federal Open Market Committee, for his dovish policy stance relative to the current FOMC spectrum, and for championing the view that any future exit from expansionary policy should be based on actual economic conditions rather than the calendar. That said, Blinder questioned the paper's implication that there exists a single, invariant Taylor rule on which the committee focuses. He recalled from his own FOMC tenure that the committee looked at as many as a dozen variations of the Taylor rule, whose prescriptions for the federal funds rate often differed across a range of 150 basis points-at a time when the incremental change in the rate under discussion was usually 25 basis points. 
Blinder also expressed skepticism about the Chicago Federal Reserve Bank's macroeconomic model. That model, like others in the class of models to which it belongs, uses the rational expectations hypothesis of the term structure to nail down how a policy commitment to a particular short-term interest rate for a period of time affects long-term rates. Although plausible as theory, empirical analysis has found this view of the term structure to be completely wrong: it has never been shown to hold in any country for any period longer than a quarter or two.

David Romer, responding to Blinder's first point, proposed that economists henceforth use the term "interest rate rule" instead of "Taylor rule." One is less tempted to put a "the" in front of the latter, he observed.

Donald Kohn agreed with Romer that the Federal Reserve's forward guidance to date has been intended not as announcing a deviation from its chosen interest rate rule, but rather as clarifying what the interest rate rule was and how the Fed views the economic outlook. Kohn also noted that no central bank to date has adopted an Odyssean commitment strategy, and he suggested that the reasons were at least twofold. One is simple uncertainty: the economy could change in ways that were unforeseen when the commitment was made. The other is central banks' reluctance to undermine their hard-won credibility as inflation fighters: any deliberate overshooting of the inflation target might destroy or at least erode that credibility, which would likely prove expensive to restore.

Bradford DeLong suggested that the balance sheet problem cited by Hall could be avoided if the Federal Reserve purchased less liquid assets. If, for example, instead of Treasury bills and mortgage-backed securities, the Fed invested in physical infrastructure, or student loans, or basic biomedical research, those positions would be less easily reversed and thus support a more credible commitment. Expansionary monetary policy would in effect substitute for expansionary fiscal policy, as had been argued by Gauti Eggertsson and Michael Woodford in their 2003 Brookings Paper, or indeed by Jacob Viner in the 1930s.

Refet Gürkaynak claimed that the Federal Reserve did in fact provide Odyssean forward guidance in one recent episode. Concerns about deflation in 2003-05 led the FOMC to say explicitly that it would keep interest rates low for a longer period than the markets were expecting. Indeed, many now place blame for the housing bubble on what they see as large deviations from the Taylor rule during that period. But, Gürkaynak argued, the reason the Federal Reserve kept interest rates so low during that period is that it had committed itself, or saw that it was perceived as having committed itself, to that policy, so that it became a matter of maintaining 
credibility. An interesting question, then, was whether, looking back, that episode should be seen as a success.

Laurence Meyer expressed dismay that Federal Reserve officials would even suggest that there was any uncertainty about whether the Fed's forward guidance was perceived as a commitment or as a forecast. Meyer himself had recently surveyed 100 market participants, 98 of whom understood it to be a forecast. He thought the real topic of interest in the paper was Evans's 7/3 proposal, which Meyer viewed as effectively calling on the Federal Reserve to commit itself unconditionally to keeping interest rates unchanged until the unemployment rate fell to 7 percent-in his view there was no chance that inflation would rise above 3 percent during the relevant period, so that part of the proposal was moot. For his part, Meyer believed that the FOMC would never make such an unconditional commitment. What he thought had happened in the recent episode was that the Federal Reserve had surprised the markets by revising its policy rule, as Evans had urged, to place greater emphasis on the unemployment objective relative to the price stability objective.

Michael Kiley thought it useful to clarify that a commitment strategy means one in which it is the reputation of the policymaker that is being used to influence market behavior. In his view a better taxonomy might be that of V. V. Chari, Patrick Kehoe, and Edward Prescott, who in a 1989 paper had distinguished between optimal policy under discretion and optimal policy under commitment and postulated a continuum between those two extremes. Kiley agreed with Michael Woodford that the paper should also consider simulations that test the effectiveness of their proposed strategies in response to a downward shock to inflation and economic activity; the paper at present examined only the risks to the upside.

Looking at the paper's empirical estimates of the impact of Odyssean forward guidance, Eric Swanson observed that several of the results were puzzling or had the wrong sign, as the authors themselves had recognized. He suggested that the problem was one of identification, and specifically the fact that the Odyssean component was measured as a residual, so that whatever was not Delphic was identified as Odyssean by default. Swanson was reminded of Robert Solow's well-known total factor productivity residual, which some have called "a measure of our ignorance." In fact, the authors' residual might be capturing not only the effects of Odyssean commitment but also errors due to model misspecification, differences in Taylor rules, and other influences. Swanson argued further that the Federal Reserve's recent forward guidance surely did have at least some commitment aspect. In particular, there seemed to be widespread agreement, in the 
press and elsewhere, that the Fed would now find it more difficult to raise interest rates than if it had never issued the guidance. To the extent that this was true, it was exactly the Eggertsson-Woodford story. This was also the case, he suggested, for the 2003-05 episode cited by Gürkaynak.

Responding to DeLong, Swanson argued that the fact noted by Hall, that the Federal Reserve can raise the interest rate on reserves, made it irrelevant whether the Fed purchased liquid or illiquid assets. By changing the interest rate paid on reserves, the Fed could tighten policy as quickly and by as much as it desired whatever the size or composition of the assets on its balance sheet. DeLong replied that although from a strictly economic perspective Swanson was correct, his point was that the Federal Reserve would encounter political difficulties if it realized large capital losses from the sale of illiquid assets, or if it ran large operating losses. To the extent the Fed responded to these political considerations, purchases of illiquid assets could still have a commitment effect.

Frederic Mishkin offered an example of why it was dangerous to interpret apparent deviations from a Taylor rule as a commitment. In late 2007 the economy was performing well, yet the Federal Reserve started to lower interest rates. That might have been interpreted as a deviation from the interest rate rule, and thus as a commitment to depart from standard policy, but in fact the Fed's forecast had changed dramatically, and its lowering of interest rates was intended as a normal policy response to that change. Mishkin also thought the paper should distinguish more clearly between management of expectations and commitment. Managing public expectations is part of normal Federal Reserve policymaking, and it can do this in various standard ways, or it can manage expectations through commitment.

Noting that the paper cited recent Federal Reserve estimates of the NAIRU (non-accelerating-inflation rate of unemployment), Mishkin commented that those estimates remain highly uncertain, and in his view the Fed has not emphasized that uncertainty as much as it should. Lastly, Mishkin expressed misgivings about the use of 3 percent as a comfort zone for the inflation rate: if it became widely understood that the Fed considers 3 percent annual inflation acceptable, that could easily be misinterpreted as the Fed's new target for inflation, leading to an adverse expectations dynamic that could actually harm economic performance.

Jan Hatzius observed that although the authors and the discussants had some important differences of opinion, all of them had had positive things to say about nominal GDP targeting, at least at some level. That observers from both sides of the political spectrum could agree that there was some- 
thing to be said for such a policy made him hopeful that it might serve as a basis for some sort of convergence in the future.

Christopher Sims pointed out that whether the Federal Reserve's statements are interpreted as Delphic or Odyssean, the evidence is clear that the Fed's announcements do have effects on markets, and that implies that the Fed has an information advantage over market participants. Thus, under either interpretation, there is room for discretionary monetary policy, which would not be the case if the Fed did not know anything that the markets do not already know.

Sims disagreed, however, with those who said that the Federal Reserve can always switch to a contractionary policy, no matter how large its balance sheet, just by raising interest rates. What might give the Fed pause in such circumstances, he argued, was not its own balance sheet but the Treasury's: given today's large federal debt, any sharp rise in interest rates would have a dramatic effect on federal interest expenditure, exceeding any seen in the postwar period. At a minimum that would have unpredictable political consequences for the Fed. Such a scenario might be of even greater concern in Europe: the European Central Bank's balance sheet has likewise been greatly expanded, yet unlike in the United States the political repercussions of its raising interest rates would be spread over a large number of uncoordinated fiscal policymakers.

Andrew Levin returned to Michael Kiley's point about the continuum between discretion and commitment. Perfect commitment, he argued, is possible only for a Ramsey policymaker who has complete authority, lives forever, and communicates perfectly and with complete credibility. Such a policymaker does not exist in the real world. The United States, for example, has periodic elections, and the president appoints and the Congress confirms the Federal Reserve chairman and many of the FOMC members. Hence the Fed cannot commit itself for any period longer than a few years. This absence of an immortal monetary autocrat may be bad from an economic perspective but is surely good from a political one: we value democracy. This limit to the ability to commit does not, however, mean that any stated commitment by the Fed is just cheap talk: in the United States as in most of the industrialized world, a strong democratic consensus has formed behind the institution of independent central banks. For Levin the question was whether the central bank can articulate its favored policies in a way that strengthens that consensus, thus allowing it to move further along the continuum toward optimal commitment. 
Responding to the discussion, Charles Evans acknowledged that the paper's analysis of Delphic versus Odyssean statements was not intended as a pure decomposition, but rather was an attempt to get at an important distinction, namely, between what part of any effect of the Federal Reserve's forward guidance represents the announcement of a change in its outlook and what part represents something beyond that. An important point, Evans thought, was that adopting state-contingent policies does make a great deal of sense given that one cannot easily separate the Delphic from the Odyssean.

Evans defended the $7 / 3$ threshold as an attempt to control for inflation risk while trying with the other hand to stimulate the economy. It is also an admission that we do not know exactly what the right model of the economy is. Evans recalled that he had recently attended an ECB meeting in Frankfurt where the claim was made that economists are so enamored of their models that they come to believe that the world works just as their models describe. When his turn came to speak, Evans had countered that although to him the real-world evidence today cried out for more monetary accommodation, the purpose of economic modeling was precisely to identify the factors that could render that conclusion wrong. The great thing about a model, in his view, was that it can be put on the table and dissected, and areas of disagreement can be specified and debated. In the absence of a shared model like that which the Federal Reserve Board staff prepare for every FOMC meeting, participants have a free pass to criticize various policy options without having to back up their views. Finally, Evans noted, given that one has to have a model of the economy, that model has to include monetary policy itself: there has to be a response function of some kind, and it has to be one that can survive confrontation with the data. 